University of Louisville

ThinkIR: The University of Louisville's Institutional Repository

Electronic Theses and Dissertations

$12-2016$

\title{
Pro-inflammatory cytokines promote viral replication and cell cycle mediators in arenavirus-induced hepatitis.
}

Gretchen E. Holz

University of Louisville

Follow this and additional works at: https://ir.library.louisville.edu/etd

Part of the Virus Diseases Commons

\section{Recommended Citation}

Holz, Gretchen E., "Pro-inflammatory cytokines promote viral replication and cell cycle mediators in arenavirus-induced hepatitis." (2016). Electronic Theses and Dissertations. Paper 2616.

https://doi.org/10.18297/etd/2616

This Master's Thesis is brought to you for free and open access by ThinkIR: The University of Louisville's Institutional Repository. It has been accepted for inclusion in Electronic Theses and Dissertations by an authorized administrator of ThinkIR: The University of Louisville's Institutional Repository. This title appears here courtesy of the author, who has retained all other copyrights. For more information, please contact thinkir@louisville.edu. 


\title{
PROINFLAMMATORY CYTOKINES PROMOTE VIRAL REPLICATION AND CELL CYCLE MEDIATORS IN ARENAVIRUS-INDUCED HEPATITIS
}

\author{
By \\ Gretchen E. Holz \\ B.A., Indiana University, 2007 \\ A.A., Indiana University, 2012 \\ A Thesis \\ Submitted to the Faculty of the \\ School of Medicine of the University of Louisville \\ in Partial Fulfillment of the Requirements \\ for the Degree of \\ Master of Science \\ in Pharmacology and Toxicology \\ Department of Pharmacology and Toxicology \\ University of Louisville \\ Louisville, Kentucky
}

December 2016 



\title{
PROINFLAMMATORY CYTOKINES PROMOTE VIRAL REPLICATION AND CELL CYCLE MEDIATORS IN ARENAVIRUS-INDUCED HEPATITIS
}

\author{
By \\ Gretchen E. Holz \\ B.A., Indiana University, 2007 \\ A.A., Indiana University, 2012 \\ A Thesis Approved on
}

November 21, 2016

by the following Thesis Committee:

Igor Lukashevich, M.D., Ph.D.

Donghoon Chung, Ph.D.

Matthew Cave, M.D., Ph.D. 


\section{DEDICATION}

This Thesis is dedicated to my husband, Travis, for his patience and companionship throughout my academic journey, and to my parents, Diane and Nick, who have provided unwavering support and encouragement in all of my life endeavors. 


\section{ACKNOWLEDGEMENTS}

I would like to thank Dr. Lukashevich for bringing me into his lab and giving me the chance to learn about viruses and work in biosafety level 3-this is one of the coolest things I have ever done and I will always remember what it was like to do research and experiments in containment, very cool indeed! Also thank you to Dr. Cave for your insights on my thesis project and providing your much needed hepatic knowledge. Thank you to Dr. Chung also for always being the calm and focused voice guiding the next important and logical experiment. I always appreciate your perspective, willingness to help and provide your virology knowledge, and your approachability in the lab-l could always find you somewhere in the lab working on your experiments and get a quick piece of advice for my experiments. I also very much appreciated Dr. Chung's ability to boost my morale and confidence in my results, which was very important in the thesis writing and presenting my work for the defense.

Furthermore, I must thank Dr. Sokoloski for lending his time, effort, and expertise in sewing up the final stitches of this project and thesis writing. I truly appreciate the guidance, confidence-boosting, virus knowledge, and motivation he provided in the final weeks of preparation. He was central to helping me get over the finish line at the end.

Thank you also to Dr. Beverly for taking a chance on me-a complete rookie to laboratory research—and bringing me into his lab. I appreciate his 
time and patience in teaching me about cell culture, Western blots, animal research and so much more. I also appreciated working for a "cool" scientist and not a "dork," as he pointed out, and our lab meetings that always included beer. This was great introduction experience into the world of scientific research.

Thank you also to my lab family, Jenny-the best lab mom ever!-and Nikki. Jenny always motivated me to work harder, get to work earlier, and stand up for myself. She always advocated for me, like a mom would do, and I sincerely appreciated her willingness to stand up for me and reinforcing the need to believe in myself. Ms. Nikki has been the absolute best lab-mate and best friend anyone could ask for, in any situation really, but especially during graduate school. We went through a lot together, but always had each other's back. I always appreciated her optimism and ability to move forward and let go of the bad and embrace what's next. We laughed a lot, and actually cried a lot too, and she was such a key part of me sticking with this journey and getting through all of the hard times-I must thank her for keeping me on track.

Also thank you to next door lab neighbor, Mr. Scott, for his honesty and genuine personality. I have truly appreciated and grown from all of our long conversations about the meaning of life, music interests, pets, sports, and all of the weird topics. Thank you also to Zimple for being a good friend, for also taking her free time to provide guidance and support, and also for helping me cross the finish line. 


\begin{abstract}
PROINFLAMMATORY CYTOKINES PROMOTE VIRAL REPLICATION AND CELL CYCLE MEDIATORS IN ARENAVIRUS-INDUCED HEPATITIS

Gretchen E. Holz
\end{abstract}

November 21, 2016

Lassa virus (LASV) is an arenavirus and causative agent of Lassa fever (LF), a viral hemorrhagic fever in West Africa for which there is no vaccine. Lymphocytic choriomeningitis virus (LCMV), is used as a surrogate to mimic LASV-induced liver pathology. LCMV-WE, not LCMV-ARM, causes disease in primates and mice characterized by hepatitis, high viral load, hepatocyte proliferation, and upregulated proliferative triggers (e.g. TNF- $\alpha$, IL-6 ). We hypothesize LCMV-WE induces pathological hepatocyte proliferation via proinflammatory triggers (TNF- $\alpha$, IL-6) from macrophages, leading to: increased viral replication, modulated cell cycle, and arrested cell cycle. RAW 264.7 macrophages and AML-12 hepatocytes, were used as models for liver cells and infected with LCMV. High LCMV-WE titers in RAW 264.7 resulted in upregulated TNF- $\alpha$. LCMV-WE infection with TNF- $\alpha$ enhanced viral replication and modulated cell cycle, leading to arrest. Livers of fatal LASV-infected marmosets also displayed high viral load, IL-6, and upregulated p21, validating cell cycle arrest as key hepatic event. Altogether, these results validate AML-12 hepatocytes to study mechanisms of arenavirus-induced hepatitis. 


\section{TABLE OF CONTENTS}

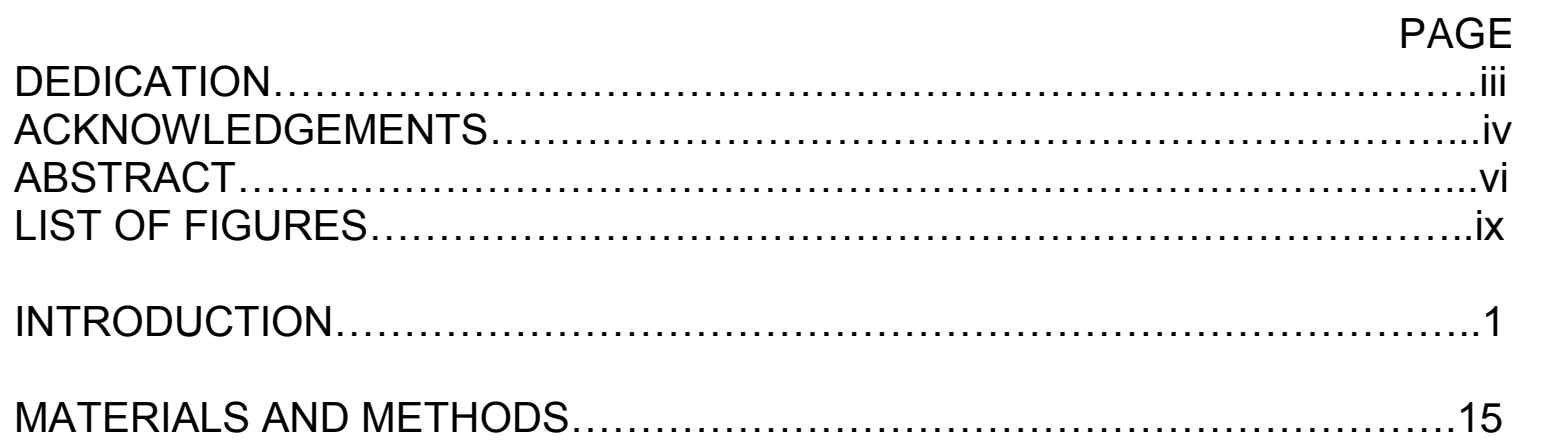

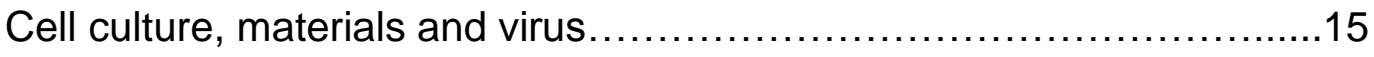

LCMV growth kinetics.................................................. 16

TNF- $\alpha$ stimulation and LCMV infection in AML-12 ..................... 16

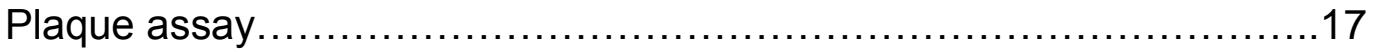

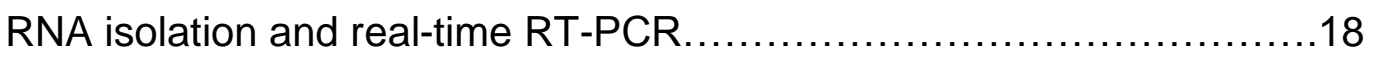

TNF- $\alpha$ Enzyme-linked immunosorbent assay ...........................20

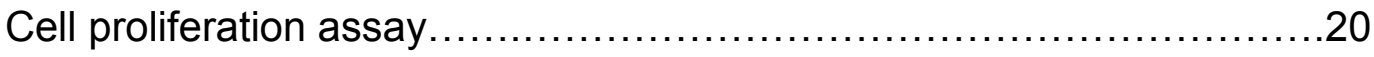

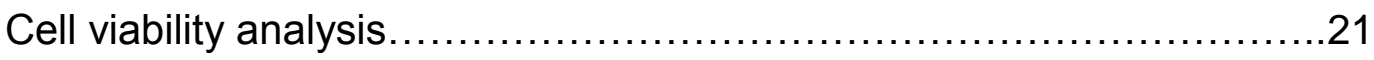

Statistical Analyses................................................... 21

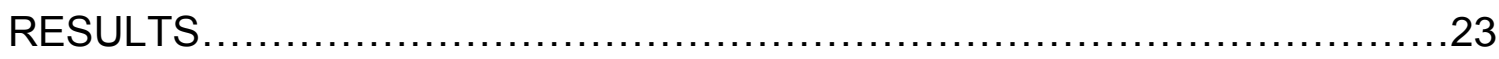

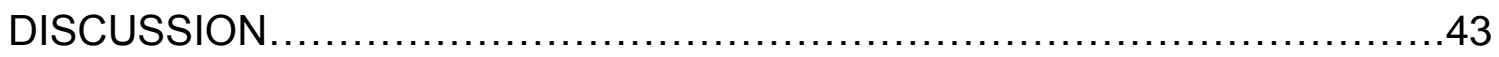

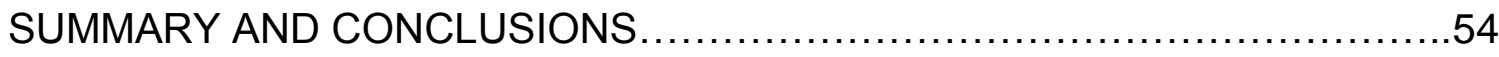

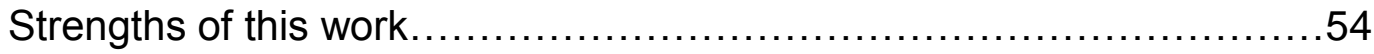

Unanswered questions and future directions ...........................55

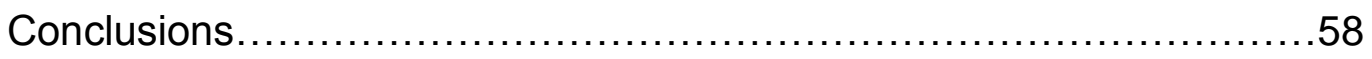


REFERENCES.

.60

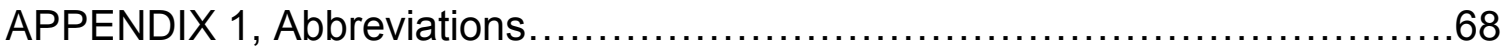

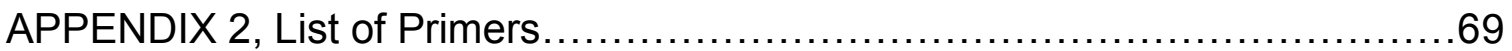

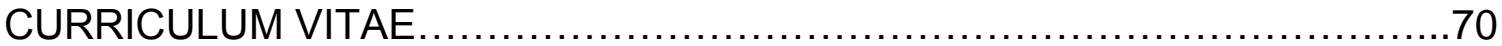




\section{LIST OF FIGURES}

FIGURE

PAGE

1. LCMV infects and efficiently replicates in RAW 264.7 macrophages and AML-12 hepatocytes.

2. Replication of LCMV-WE in RAW 264.7 macrophages associated with induction of proinflammatory cytokines.

3. TNF- $\alpha$ induces proliferation without affecting cell viability in AML-12 hepatocytes.

4. TNF- $\alpha$ enhances LCMV-WE replication in AML-12 hepatocytes 33

5. TNF- $\alpha$ with LCMV-WE infection induces $\mathrm{G}_{1} / \mathrm{S}$ phase cell cycle mediators in AML-12 hepatocytes.

6. High viral load and upregulated pro-inflammatory IL-6 correlated with cell cycle arrest in livers of NHPs fatally-infected with LASV 


\section{INTRODUCTION}

Arenaviruses and Public Health

Hemorrhagic fever viruses (HFVs) are a diverse group of RNA viruses that cause severe disease known as viral hemorrhagic fevers (VHFs). Principal symptoms of VHFs include fever, vascular system manifestations, multi-organ failure and sepsis-like cardiovascular collapse. Members of many prominent RNA virus families are defined as HFVs, including Arenaviridae, Bunyaviridae, Filoviridae, Flaviviridae, and Rhabdoviridae, which are responsible for causing VHFs like Lassa fever, hemorrhagic fever with renal syndrome, Ebola hemorrhagic fever, Dengue hemorrhagic fever, and Bas-Congo hemorrhagic fever, respectively. VHFs have a significant impact on public health worldwide and cause over 100 million infections per year [1]. Though VHFs create a substantial medical burden, the availability of treatments and vaccines remain limited, with some notable exceptions for Yellow fever and Argentine hemorrhagic fever (i.e. Yellow fever 17D vaccine and Candid\#1 vaccine). Thus, given the lack of effective treatment options coupled with the threat of HFVs being used as biological weapons, the National Institutes of Allergy and Infectious Disease (NIAID) consider HFVs Category A priority pathogens [2]. While HFVs come from distinct viral families, they share key characteristics, including similar mechanisms of infection and pathology in their hosts [3-5]. 
The Arenaviridae, a fast growing family of rodent-borne viruses, has the highest number of HFVs with a significant impact on human health in endemic areas $[1,6]$. Researchers recently discovered arenaviruses not only infect mammals, but they also infect reptiles (i.e. boid snakes) [7-9]. Based on this discovery, the Arenaviridae family is divided into two genera, Mammarenavirus and Reptarenavirus [10]. (NOTE: Mammarenaviruses will be colloquially referred to as "arenaviruses" from this point forward.) Arenaviruses are split into the Old World (OW) and New World (NW) virus groups based on phylogenetic, serological, and geographical differences. The OW viruses (or LASV-LCMV sero-complex) are mostly found in Africa, with the exception of LCMV, which is found all over the world. OW arenaviruses include Lassa virus (LASV), Mopeia virus (MOPV), Lujo virus (LUJV), Ippy virus (IPPYV), Luna virus (LNKV), Mobala virus (MOBV), Merino Walk virus (MRWV) and lymphocytic choriomeningitis virus (LCMV) [10]. LCMV is also considered the prototypic arenavirus. The NW viruses (or Tacaribe sero-complex) are distributed throughout the Americas and include important human pathogens that can cause hemorrhagic fever, like Junin virus, Machupo virus, Guanarito virus, Sabia virus, and Chapare virus. Tacaribe virus is considered the prototypic NW arenavirus.

The causative agent of Lassa fever (LF), LASV is the most prominent viral hemorrhagic fever (VHF) in West Africa [11]. LASV has the most influence on human health of all the HFVs (second to Dengue virus in terms of morbidity), causing over 300,000 infections per year with $5,000-10,000$ deaths annually [ 1 , $6,11]$. Though LASV is a neglected tropical pathogen with significant human 
health impact, treatment options for infection and LF disease are severely lacking. Supportive care including rehydration and attention to symptoms early in infection can improve patient prognosis. Ribavirin is a broad-spectrum antiviral drug that can be effective in treating LASV infection, but it must be taken within a few days of symptom-onset and it causes many adverse effects. With no approved vaccines or effective treatments, the World Health Organization urges that LASV is a severe HFV in need of immediate research attention to facilitate development of antiviral therapies and interventions.

Humans become infected with LASV mainly by contact with infected rats, food, or items contaminated with rodent excreta (e.g. feces, urine, etc.) from the virus's natural reservoir, Mastomys natalensis, a multimammate rat found in subSahara Africa [11]. Spread of the virus also happens between humans, through direct contact with contaminated bedding, soiled clothing, or bodily fluids of infected person. Moreover, hospital-contracted infections also occur [12]. After initial contact with LASV, LF symptom onset occurs within 2-21 days. Disease severity can vary from asymptomatic infection to mild LF symptoms early on, which are similar to those of other common illnesses and include sore throat, fever, malaise, and headache. Nausea, vomiting, diarrhea, and abdominal pain, as well as vascular abnormalities (e.g. hemorrhaging found in the mouth, nose, gastrointestinal tract, and vagina) are associated with progressed LF disease. In later stages of disease, seizures, coma, tremor, and shock are observed, which are evident of multi-organ syndrome and can lead to death. 
Arenavirus Molecular Biology

Arenaviruses are enveloped, single-stranded RNA viruses that use a negative ambisense coding strategy (i.e. one gene segment on each strand is $5^{\prime}$ - $3^{\prime}$ and the other gene segment is $3^{\prime}-5^{\prime}$ and must be replicated before transcription) [13-16]. The arenavirus genome consists of two segments, large $(\mathrm{L})$ and small $(\mathrm{S})$, each encoding two proteins. The $\mathrm{L}$ segment encodes the $\mathrm{L}$ polymerase protein and the $Z$ matrix protein [15]. The $L$ protein, the RNAdependent RNA polymerase (RdRp) is responsible for transcription of the viral genome and replication of the virus. The $Z$ protein is a zinc-binding protein that plays a regulatory part in replicating viral RNA, reviewed in [17]. The S segment encodes the glycoprotein complex (GPC), which is post-translationally cleaved into GP1 and GP2, and the nucleoprotein (NP) $[18,19]$. GP1 is the viral attachment protein that interacts with the host cell receptor, and the GP2 is involved in $\mathrm{pH}$-dependent endocytosis. Heavily involved in regulating the processes of transcription and replication of the viral genome, the NP protein is the most abundant protein in viral particles and in infected cells, as it encapsidates the viral genome, reviewed in [17].

Arenaviruses enter host cells through a unique pathway, reviewed in [17]. First, the viruses bind their respective receptors on host cells via the GP1 viral attachment protein and are then internalized into endosomal compartments. The research described in this thesis focuses on OW arenaviruses, which primarily use alpha-dystroglycan ( $\alpha-D G$ ) as the main viral receptor for attachment and entry into host cells [20]. After binding a-DG, OW arenaviruses enter cells via a 
unique cholesterol-dependent pathway that is independent of clathrin, caveolin, and actin, but requires microtubules. Upon internalization, LASV and LCMV-WE have been shown to by-pass early endosomal compartments, thus avoiding detection by the immune sensors in these compartments, and thus, virus-bound receptors traffic directly to late endosomes. In the late endosome, LASV switches from $\alpha$-DG to bind lysosome associated membrane protein 1 (LAMP-1) and fuses with the cell membrane to release viral RNA into the cytoplasm [21]. However, LCMV-ARM fusion with cell membrane does not require switching to LAMP-1 [21]. Viral fusion occurs at very low pH (i.e. 3.0-5.0). Viral RNA is then released into cytoplasm after viral membrane fuses with the late endosome. In the cytoplasm, the viral RNA is transcribed, translated, and the genome is replicated. Then lastly, new viral particles, or virions, are assembled at the plasma membrane, and bud from the host cell with help of the $Z$ matrix protein, among other viral and cellular proteins.

Arenavirus Infection, Pathology, and Disease

After crossing epithelial barriers at two major entry gates, the respiratory and gastro-intestinal tracts, arenaviruses primarily infect macrophages and dendritic cells (DCs) $[22,23]$. While they replicate in many tissues, the highest titers of arenaviruses are detected in the liver, spleen, lymph nodes, and adrenal glands [24, 25]. Arenaviruses replicate efficiently without killing their host cells. Efficient replication occurs in the resident macrophages in the liver called, 
Kupffer cells (KCs), and also in macrophages and DCs in the lymph nodes and spleen.

In the liver environment, KCs and hepatocytes are important targets of LASV and LCMV infections and these cell types perform vital duties within the liver [22, 26, 27]. For example, KCs intercept pathogenic material from the blood of the portal vein that is filtered by the liver. Hepatocytes have a significant role in liver function, including: metabolizing basic molecules into useful compounds, producing plasma proteins (e.g. albumin, coagulation factors), and synthesizing vital immune response proteins (i.e. acute phase, TLRs, inflammatory cytokines, chemokines and complement). The liver is constantly exposed to the environment, including antigens delivered via portal vein (from the gastrointestinal tract) and from hepatic artery (systemic), and must maintain immune-tolerance, as reviewed in [28]. Yet, it is a delicate balance because while it must retain immune-suppression toward the constant exposure to gutderived materials, the liver must also retain immune-responsiveness to bloodborne pathogens and microbes that circulate into the liver. Moreover, the liver plays a significant role in immunity, also reviewed in [28]. The liver is a dynamic organ in the body characterized by its metabolic and detoxifying abilities, in addition to balancing immune responsiveness with immune tolerance, which not only makes it a good target for viral infection, but also a key target involved in disease progression.

From the liver, lymph nodes, and spleen, arenavirus infection spreads systemically throughout the body. However, the pathogenesis of LF disease is 
still uncertain because the tissue damage caused by direct infection in the target tissues is not severe enough to implicate organ failure as the cause of death [24, $25,29,30]$ In fact, death from LF is caused mostly by uncontrolled sepsis-like terminal cardiovascular shock.

Liver pathology is the prominent finding from fatal LASV infection. As described above, the evidence of severe tissue damage and overt pathology in fatal LF disease is infrequent and not extensive; however, the histological abnormalities that are observed during fatal LF are the most pronounced in the liver, which include multifocal necrosis and areas of hepatocyte proliferation [25, 29]. To this end, healthcare workers described the first clinical cases of fatal Lassa fever as "Lassa virus hepatitis" [29]. High levels of serum aspartate aminotransferase (AST), which is commonly used in conjunction with alanine aminotransferase (ALT) levels as biomarkers of liver health, are hallmarks of LASV infection [25, 29]. Furthermore, serum AST levels above $120 \mathrm{IU} / \mathrm{L}$ in hospitalized patients were shown to correlate with poor prognosis. Johnson KM et al. also found that viremia, or uncontrolled systemic infection, was associated with fatal LASV infection; but progressive control of viremia was found in survivors of LASV infection [24]. These studies concluded there is a key correlation between serum levels of ASTs and viremia, and the prognosis of the patient. Patients with viremia and ASTs below $150 \mathrm{IU} / \mathrm{L}$, were more likely to survive infection. However, patients with viremia $\left(>3 \log \mathrm{TC}_{\mathrm{ID}} 50 / \mathrm{mL}\right)$ and ASTs greater than $150 \mathrm{IU} / \mathrm{L}$, were more likely to die from LF disease. Past research from cases of human LASV infection has also shown pathological hepatocyte 
proliferation in liver tissue $[25,29,30]$. Fatal Lassa fever patients showed evidence of LASV replication in hepatocytes [29, 30], evidence of mitosis [25], and liver damage and regeneration, with three progressive and distinct phases: 1) active hepatocyte injury, 2) continued damage and early recovery, and 3) hepatocyte regeneration [29]. Thus, while damage to other tissues besides the liver can also contribute to elevated AST levels, altogether, it is clear that liver pathology characterized by hepatocellular damage and proliferation plays an important role in LF pathogenesis and is linked to uncontrolled viral replication.

However, mechanisms behind the disease pathogenesis and liver pathology caused by LASV are poorly understood. Moreover, LASV is a biosafety level 4 pathogen requiring high containment research facilities, which are found in limited locations in the United States. Thus, the prototypic arenavirus, LCMV, has been shown to mimic LASV-induced liver pathology when used as a surrogate virus in experimental models, reviewed in [31]. LCMV is a well-studied virus in research models, including in vivo and in vitro models of infection. Studies of LCMV infection in mice has provided an understanding of basic concepts in immunology, like acute versus persistent viral infection, MHC restriction, $\mathrm{T}$ cell memory, $\mathrm{T}$ cell exhaustion, among other important immunological concepts $[13,32-35]$. The in vitro experiments described in this thesis use two different strains of LCMV, LCMV-WE (strain 54) and LCMV-ARM strain 53b). LCMV-WE is the viscerotropic strain known for its tropism to the liver and virulence in non-human primates (NHPs) [26, 36], guinea pigs [14], and also liver tropism is documented in mice [37]. In fact, previous studies showed 
LCMV-WE infection in experimental NHP models induced a fatal LF-like disease characterized by liver dysfunction and robust hepatocyte proliferation [26, 38]. LCMV-ARM, highly adopted to mice and tissue culture, is a neurotropic strain. Though it shares $88 \%$ amino acid homology with LCMV-WE [39], LCMV-ARM strain does not induce disease in NHPs nor exhibit tropism to the liver in NHPs, guinea pigs, and mice. Therefore, LCMV-ARM is a good control against the liver pathology induced by LCMV-WE.

NHPs infected with arenaviruses further demonstrate the critical importance of the liver during infection. Previous outbreaks of LCMV infection in zoo-kept New World primates (e.g. marmosets, tamarins) provide further evidence of targeting the liver. Tamarins and marmosets housed in zoos in North America and Germany were inadvertently fed newborn mice infected with LCMV, which caused a severe and fatal infection in the monkeys called Callitrichid hepatitis [40, 41]. The histopathological observations showed extensive hepatitis in the livers of fatally-infected monkeys. Also, studies showed that experimentally-infected NHPs with LASV and LCMV-WE succumbed to a severe, LF-like disease. Though histopathology in liver showed only spotty hepatocellular necrosis and mild inflammation, severe infections were characterized by high viremia $\left(>10^{\wedge} 5 \mathrm{PFU} / \mathrm{mL}\right)$, interleukin 6 (IL-6), and soluble IL-6 and TNF receptors in plasma, and also liver pathology that included high levels ( $>5$-fold) of AST and ALT enzymes, hepatocyte proliferation and liver dysfunction [26, 27, 36, 38, 42, 43]. LASV and LCMV-WE infections in NHPs demonstrated that KCs and hepatocytes were also clear targets of infection. 
Showing viral antigens in both cells, which populate the majority of the liver, lends more detailed support to data revealing the livers had the highest viral load all of tissues during terminal illness [26, 27, 43].

Furthermore, experimentally LCMV-infected mice represent a welldocumented model capable of demonstrating clear differences in tropism; as LCMV-WE causes transient hepatitis, while LCMV-ARM does not. Similar characteristics of liver pathology found with LCMV-WE infection in NHPs also have been noted in mice: elevated liver enzymes (AST, ALT) in plasma, viremia, and histopathology detailing spotty necrosis, mild inflammation, induction of hepatocyte proliferation, and elevated gene expression for tumor necrosis factor alpha (TNF- $\alpha) \quad[37,44,45]$. Furthermore, although KCs or resident liver macrophages were targeted early, hepatitis developed when hepatocytes were targeted more exclusively later in infection [44]. We previously observed in mice that LCMV-WE caused transient hepatitis and liver pathology characterized by robust hepatocyte proliferation without hyperplasia, cell cycle arrest, and strong upregulation of hepatic tumor necrosis factor alpha (TNF- $\alpha$ ) expression [45]. Notably, while IL-6 was shown to be a key biomarker of severe infection in NHPs, TNF-a, however, was an important pro-inflammatory signal robustly upregulated in the livers of mice infected with LCMV-WE.

Collectively, our results proposed a novel mechanism of arenavirusinduced liver pathology in which activation of hepatocyte proliferation resulted in arrested cell cycle and down-stream events (e.g., IFN-gamma up-regulation, apoptosis, oval cell activation), further contributing to the pathogenesis of 
arenavirus-induced hepatitis. These findings of cell cycle arrest were novel and highly intriguing, bringing about more questions concerning viral mechanisms: is cell cycle arrest a true viral mechanism or is it an artifact of using a murine model?

Cell Cycling Modulation, a Common Strategy in Viral Replication

Manipulating host cell cycle for viral benefit is a commonly employed pathogenic mechanism for RNA viruses. Several RNA viruses have been shown to manipulate cell cycle mediators and movement through the first gap phase $\left(\mathrm{G}_{1}\right)$ to increase viral replication [46-50]. Progression through $\mathrm{G}_{1}$ is controlled by phosphorylation of retinoblastoma protein $(\mathrm{pRb})$ via binding of D-type cyclins and cyclin-dependent kinases (CDK) 4 and 6 complex. Movement into and through S phase is associated with increasing levels of cyclins $A$ and $E$, with both cyclins forming complexes with CDK2 to further phosphorylate pRb, reviewed in [51]. Furthermore, enhanced viral replication and viral proteins have also been correlated with accumulation of markers for cell cycle arrest, like tumor suppressor protein p53 and CDK inhibitor (CKI) p21. The active form of p53 is responsible for, among other effects, initiating the transcription of p21, reviewed in [51]. An important inhibitor of $\mathrm{G}_{1} / \mathrm{S}$ phase transition, $\mathrm{p} 21$ is a $\mathrm{CKI}$ that binds to and inhibits activity of CDK2-cyclin E complex, which inhibits cell cycle progression to S phase, resulting in cell cycle arrest, reviewed in [52]. While there is evidence of other RNA viruses' manipulation of cell cycle at $G_{1}$ phase, OW arenaviruses use a very unique mechanism of manipulating cell cycle. They 
first induce pathological cell cycle in hepatocytes, and then subsequently inhibit cycling by inducing cell cycle arrest. This unique mechanism is examined in this thesis using in vitro hepatocytes. Along with this mechanism, a non-conventional receptor for viral entry into host cells, Axl, was examined to determine altered cell cycle effects on gene expression of known entry factor for the virus. Given the reproducibility, and molecular evidence of cell cycle modulation during arenavirus infection, we propose that cell cycle modulation is a key facet of arenavirus replication.

Arenavirus Infection Induces Cytokine Expression

Pro-inflammatory cytokines and receptors involved in triggering hepatocyte proliferation are found to be upregulated in the livers and plasma of human LASV and experimental LCMV-WE infections [26, 27, 43, 53]. Hepatocyte proliferation is a highly conserved and coordinated sequence of events generally reserved for repairing a severely damaged liver-from partial surgical removal, hepatic toxins, or infection. While hepatocytes do not cycle or divide under normal circumstances, they have the ability to undergo cell cycle in response to specific signals, reviewed in [54]. KCs are responsible for producing cytokines, including pro-inflammatory TNF- $\alpha$ and IL-6, which are important signals involved in the "priming phase" of preparing hepatocytes to respond to growth factors that trigger proliferation after liver injury [55-57]. Liver regeneration studies have indicated production of these cytokines is stimulated by lipopolysaccharide (LPS) coming from the enteric system and binding its toll- 
like receptor (TLR) on KCs [58-60]. In contrast, other research suggests signaling through the LPS receptor on KCs--TLR4 and TLR2-are not required for production of pro-inflammatory signals needed for liver regeneration [61]. Importantly, therefore, it is clear that significant liver damage is a trigger necessitating the highly-coordinated and timely events that result in liver regeneration.

Therefore, it is poorly understood why or how LASV and LCMV-WE infections stimulate such robust hepatocyte proliferation responses in livers displaying only spotty necrosis and mild inflammation. It is evident, as previously mentioned, that infection produces high levels of IL-6 and receptors for TNF- $\alpha$ and IL-6 in circulation and in the liver. As the main producers of proinflammatory cytokines in the liver and target of LASV and LCMV-WE, KCs are potentially the source of transient TNF- $\alpha$ and IL-6 responsible for triggering pathological hepatocyte proliferation. While research has shown LASV and LCMV-WE infection is immune-suppressive in macrophages [22, 26, 62, 63], the timing and concentration of pro-inflammatory cytokines are two important factors that can lead to profoundly different outcomes, reviewed in $[64,65]$. In fact, TNF$\alpha$ levels are increased transiently after surgical partial hepatectomy $[56,66,67]$ and its "priming" effects on preparing hepatocytes for proliferation are gone after 48 hrs [60]. In the liver, varying TNF- $\alpha$ levels can stimulate cell apoptosis, cytokine production, and proliferation [68]. In this thesis, pro-inflammatory responses are assessed after LCMV infection in macrophages in vitro to determine OW arenavirus's ability to directly trigger proliferative cytokines. 
The objective of this work is using in vitro models to investigate the mechanisms involved in arenavirus-induced pathological hepatocyte proliferation. We show evidence that viral replication in macrophages induces proinflammatory cytokines involved in hepatocyte proliferation. Furthermore, we show that TNF- $\alpha$ stimulation along with LCMV-WE infection of hepatocytes results in enhanced viral replication and manipulation of cell cycle with evidence of cell cycle arrest. Lastly, these in vitro findings were generally supported in an in vivo model. Liver tissue from marmosets fatally-infected with LASV displayed robust elevation of pro-inflammatory cytokine associated with hepatocyte proliferation, high viral load, and upregulation of cell cycle inhibitor suggestive of cell cycle arrest. 


\section{MATERIALS AND METHODS}

A. Cell culture, materials, and virus. RAW 264.7 murine macrophages (ATCC, TIB-71), AML-12 murine hepatocytes (ATCC, CRL-2254), and Vero E6 cells monkey kidney cells (ATCC, CRL-1586) were purchased from ATCC. RAW 264.7, mouse leukaemic macrophage cells, and Vero E6, African green monkey kidney epithelial cells, were cultured in DMEM/F-12 with L-glutamine, HEPES (Gibco) supplemented with 10\% heat-inactivated FBS and $1 \%$ antibioticantimycotic (Gibco). AML-12 cells are non-tumorigenic, murine hepatocytes isolated from the liver of mice transgenic for human TGF-a [69]. These cells were cultured in DMEM/F-12 with L-glutamine, HEPES (Gibco) supplemented with $10 \%$ FBS, $1 \%$ antibiotic-antimycotic, $0.02 \%$ insulin, transferrin, selenium (ITS), and 40ng $/ \mathrm{mL}$ dexamethasone. Recombinant mouse TNF- $\alpha$ (R\&D Systems) diluted in serum free DMEM was used at different concentrations for stimulation of AML-12. LCMV-ARM strain 53b and LCMV-WE strain 54, were used for infection of all tested cells at a multiplicity of infection (MOI) of 1 PFU per 10 cells or $0.1 \mathrm{MOI}$. To make virus stocks: Vero E6 cells were infected with LCMV-ARM (53b) or LCMV-WE (54) at 1 PFU per 1000 cells for $1 \mathrm{hr}$ at $37^{\circ} \mathrm{C}$. Media used for virus stocks contained 2\% FBS. Virus stocks $\left(1 \times 10^{7}-1 \times 10^{8}\right.$ $\mathrm{PFU} / \mathrm{mL}$ ) were harvested in cell-free media, without detectable levels of cytokines and stored at $-80^{\circ} \mathrm{C}$ until use. 
B. LCMV growth kinetics. For growth kinetics experiments, cells were seeded at $2.5 \times 10^{5}$ cells $/ \mathrm{mL}$ on 12-well plates in normal media and cultured for $1 \mathrm{~d}$. Before infections, cells were washed twice with cold, serum-free media (SFM) and then infected with $0.1 \mathrm{MOI}$ LCMV-WE or LCMV-ARM for $1 \mathrm{~h}$ at $37^{\circ} \mathrm{C}$, with rocking every $15 \mathrm{~min}$. Mock-infected, control cells were treated with SFM for $1 \mathrm{hr}$, rocking every 15 min also. After $1 \mathrm{hr}$, unattached virus was removed, cells were washed twice and incubated in maintenance media (DMEM supplemented with $2 \%$ FBS and antibiotic-antimycotic) at $37^{\circ} \mathrm{C}$ until termination.

C. TNF- $\alpha$ stimulation and LCMV infection in AML-12. AML-12 cells were seeded at confluency, $5 \times 10^{5}$ cells/well in 12 -well or $4 \times 10^{4}$ cells/well in 96 -well plate and cultured for $1 \mathrm{~d}$ in normal media. Cells were then washed twice and incubated in low serum media (0.5\% FBS in DMEM with antibiotic-antimycotic) to growth arrest/synchronize cells for $2 \mathrm{~d}$ (modified protocol from [70]). Cells were then stimulated with TNF- $\alpha$ (200 $\mathrm{ng} / \mathrm{mL}$ or otherwise indicated) in SFM for $4 \mathrm{hrs}$ to initiate priming phase and ready cells for proliferation, with addition of FBS media. Before infections, cells were washed twice with cold, SFM. Cells were infected with $0.1 \mathrm{MOI}$ LCMV-WE or LCMV-ARM for $1 \mathrm{~h}$ at $37^{\circ} \mathrm{C}$, with rocking every 15 min. Mock-infected and TNF-a-only stimulated cells were treated with SFM for $1 \mathrm{hr}$, rocking every $15 \mathrm{~min}$. For experiments with TNF-a, a 5\% FBS media with TNF- $\alpha$ (200 $\mathrm{ng} / \mathrm{mL}$ or otherwise indicated) was put back on cells until termination. BrdU cell proliferation assay was performed as indicated below, or supernatants and cells were collected at indicated time points post-infection for 
plaque assay and RNA isolation, respectively, and stored at $-80^{\circ} \mathrm{C}$ until further analysis.

C. Plaque assay. The work described in this thesis uses plaque assay to quantitate infectious viral particles and determine viral titers. Here is a brief overview of the plaque assay technique, adapted from Shurtleff et al [71]:

Supernatants collected from infected cells are examined using plaque assay to determine and quantitate infectious virus. This assay begins with serially diluting experimental supernatants that contain an unknown concentration of virus in order to get a countable range of virus particles. Permissive host cells grown in a monolayer are then inoculated with viral dilutions. Vero cells are utilized as the host cells for plaque assay to test many different species of viruses because they are interferon-deficient and do not produce interferon alpha or beta in response to viral infection [72]. An overlay media containing agarose or methyl cellulose is put back on cells in order to contain virus infection to infected and adjacent cells, which will ultimately allow visible plaque formation in the cell monolayer. The cells are then incubated in this overlay media for 5 days and then cells are fixed with paraformaldehyde. They are stained with a dye, like crystal violet or neutral red, which will be taken up by all viable or uninfected cells. In the case of arenaviruses, this plaque is not due to cell death, but rather due to altered cell physiology and inability of infected-cells to take up the dye [31]. Lastly, the visible plaques in the monolayer are counted and then used to calculate the amount of infectious virus or viral titers from the experimental sample. 
As mentioned above, plaque assay was used in this work to determine viral titers of collected supernatants from experimental samples. Vero E6 cells were seeded at $1.4 \times 10^{5}$ cells $/ \mathrm{mL}$ in 12-well tissue culture plates and incubated at $37^{\circ} \mathrm{C}$ in $5 \% \mathrm{CO}_{2}$ for $48 \mathrm{hr}$. Cells were washed twice with cold, serum-free DMEM without phenol and infected with serially-diluted supernatants for $1 \mathrm{hr}$ in a humidified chamber at $37^{\circ} \mathrm{C}$ in $5 \% \mathrm{CO}_{2}$, with rocking every 15 min. Cells were then washed twice with warm culture medium containing 5\% FBS. An overlay solution was applied consisting of $1 \mathrm{X}$ minimal essential media, sodium bicarbonate, glutamine, $2 \%$ FBS, and $0.5 \%$ agarose. Cells were incubated in a humidified chamber at $37^{\circ} \mathrm{C}$ in $5 \% \mathrm{CO}_{2}$ and terminated $5 \mathrm{~d}$ later. Cells were fixed in $4 \%$ paraformaldehyde for $20 \mathrm{~min}$ at room temperature, then washed twice with PBS and stained with $0.1 \%$ crystal violet in PBS for 20 min at room temperature. Crystal violet stain was washed out of wells one time with water. Last, plaque forming units (PFU) per $\mathrm{mL}$ were determined: by counting the visible plaques for each dilution and calculating (avg. \# of plaques / volume of inoculum) * dilution factor $=\mathrm{PFU} / \mathrm{mL}$.

\section{RNA isolation and Quantitative Reverse Transcription-Polymerase Chain}

Reaction. RNA was isolated from in vitro cells by using a phenol and guanidinium thiocyanate solution (RNA-Stat 60, Tel-Test). Cells were lysed by directly applying RNA STAT-60 to cells in tissue culture plates. RNA was extracted using chloroform and centrifugation to separate RNA from DNA and protein. Isopropanol was used to precipitate RNA and then washed twice in ethanol. RNA concentrations were determined spectrophotometrically and $1 \mu \mathrm{g}$ 
total RNA was reverse-transcribed to make cDNA using a kit (Quanta Biosciences). The cellular mRNA expression of target genes was determined by using quantitative reverse-transcription polymerase chain reaction (qRT-PCR). Primers and probes for Tnf, II-6, Cdk6, Ccnd1 (cyclin D), tp53 (p53), Cdkn1a (p21), Axl, and Gapdh (mouse); IL-6, CDKN1A, AXL, and 18S (human); and CCND1 and TP53 (Rh. macaque) were purchased from Life Technologies. For list of genes with primer ID's, see Appendix 2 page 67. All primers span exonexon junctions and ensure that only cDNA and not genomic DNA was amplified. PCR reaction mix was prepared with TaqMan Fast Advanced Master Mix (Applied Biosystems). This mixture is optimized for TaqMan reactions and is a 2X concentration containing AmpliTaq Fast DNA Polymerase, Uracil-N glycosylase, dNTPs with dUTP, and a passive ROX reference. Amplification reactions were carried out using the Applied Biosystems Real-Time PCR StepOnePlus machine and software (Thermo-Scientific) with initial holding stage $\left(50^{\circ} \mathrm{C}\right.$ for $2 \mathrm{~min}, 95^{\circ} \mathrm{C}$ for 20 seconds) and 50 cycles of a 2 -step PCR $\left(95^{\circ} \mathrm{C}\right.$ for 1 second, $60^{\circ} \mathrm{C}$ for 20 seconds). Fluorescent intensity of each sample was measured at each cycle to monitor amplification of the target gene. Comparative CT method was used to determine fold changes in mRNA expression compared to an endogenous reference gene (Gapdh or $18 \mathrm{~S}$ ). Comparative CT method determines the amount of target, normalized to an endogenous reference (Gapdh or $18 \mathrm{~S}$ ) and relative to mock-infected, untreated control $\left(2^{-\triangle \Delta C T}\right)$.

For viral RNA determination from marmoset liver tissue, NP-specific primers for LASV were used for determination of viral RNA load in liver tissue. LASV-NP 
primers were purchased from Life Technologies. For specific primer/probe sequences see Appendix 2 page 67. All gene expression changes are normalized to $18 \mathrm{~S}$ endogenous control and relative to control (\#10) marmoset.

E. TNF- $\alpha$ Enzyme-linked immunosorbent assay. Supernatants were collected every 12 hpi from RAW 264.7 infected with LCMV-WE and LCMV-ARM and were analyzed for secreted TNF- $\alpha$. Detection and quantitation of murine TNF- $\alpha$ was determined using an enzyme-linked immunosorbent assay kit (R\&D Systems) according to manufacturer's protocol. Samples collected at later time points were diluted in order to obtain accurate absorbance readings within standard curve range.

F. Cell proliferation assay using BrdU incorporation. Using a modified seeding and TNF-stimulation protocol from [70], AML-12 cells were seeded at confluency, $4 \times 10^{4}$ cells $/ \mathrm{mL}$ in 96 -well plate and cultured for $1 \mathrm{~d}$ in normal AML12 media. Cells were washed $2 X$ and changed to low serum media (0.5\% FBS in DMEM with antibiotic-antimycotic) to growth-arrest and synchronize cells in cycle for $2 \mathrm{~d}$. Cells either received TNF- $\alpha(200 \mathrm{ng} / \mathrm{mL})$ in serum free media (SFM) or only SFM for $4 \mathrm{hr}$, as a priming phase before growth factors. Media containing none, $0.5 \%$, or $5 \%$ FBS, or $5 \%$ FBS + TNF- $\alpha$ was put back on cells for $24 \mathrm{hr}$. Using a cell proliferation assay kit (Cell Signaling Technology) that detects 5bromo-2'-deoxyuridine (BrdU) incorporation into cellular DNA, BrdU was added to supernatant media at $20 \mathrm{hr}$ and allowed to incorporate for $4 \mathrm{hr}$. Manufacturer's protocol was followed. Cells were fixed and DNA denatured using the kit's solutions. As a pyrimidine analog BrdU in culture media will incorporate into 
newly synthesized DNA, in place of thymidine, in actively proliferating cells. A mouse monoclonal antibody (mAb) that detects BrdU was added and then an anti-mouse secondary antibody linked to an HRP was added to recognize the mAb. TMB substrate was added lastly, which is cleaved by the HRP and causes a color change. Proliferation-specifically, cells in $S$ phase of cell cycle-is directly indicated by amount of BrdU incorporation, which is determined by magnitude of absorbance of color change.

G. Cell viability assay using Cell Titer Glo. Cells were seeded using the protocol stated in the cell proliferation assay method, above. Media containing none, $0.5 \%$, or $5 \%$ FBS, or $5 \%$ FBS +/- TNF- $\alpha$ was put back on cells for $36 \mathrm{hrs}$ at $0.1 \mathrm{~mL} /$ well. A Cell Titer Glo (Promega) assay was used to determine cell viability of AML-12 hepatocytes in different TNF and \%FBS conditions. The reagent is put directly on the cells at a $1: 1$ ratio of media to reagent (i.e. put on $0.1 \mathrm{~mL}$ reagent/well). The reagent lyses the cells and creates luminescent output proportional to the amount of ATP production from the cells, which ATP production will be indicative of the number of metabolically active cells. The luminescent signal can then be quantitated with a luminometer.

H. Statistical analysis. Experiments were performed with technical and biological replicates $(n=3)$. Student's t-tests were used to assess significant differences $(P<0.05)$ for viral replication, gene expression, cytokine production, and cell proliferation, as indicated in the figures by an asterisk $\left(^{*}\right)$. Data are presented as means \pm S.E.M. For viral replication and gene expression analyses 
in Figures 3 and $4,{ }^{*}, P<0.05$ comparing LCMV-ARM and TNF- $\alpha+$ LCMV-ARM; or comparing LCMV-WE and TNF- $\alpha+$ LCMV-WE. 


\section{RESULTS}

\section{LCMV infects and replicates efficiently in RAW 264.7 macrophages and}

\section{AML-12 hepatocytes.}

Post-mortem studies of LF patients and experimentally-infected animals showed critical involvement of liver resident macrophages (KCs) and hepatocytes in pathogenesis of arenavirus-induced hepatitis [26, 27, 29, 38, 42, 44, 45]. Recently, using mice experimentally-infected with LCMV, we documented that LCMV-WE, but not LCMV-ARM, induced transient hepatitis characterized by LCMV-WE infection in KCs and hepatocytes and upregulation of hepatic TNF-a pro-inflammatory cytokine [45].

To determine the contributions of KCs and hepatocytes in LCMV-induced hepatitis, we first examined replication kinetics of LCMV-WE and LCMV-ARM in tissue culture models, RAW 264.7 and AML-12, that mimic KCs and hepatocytes, respectively (Figure 1). Cells were infected with LCMV-WE and LCMV-ARM at $0.1 \mathrm{MOI}$ and supernatant media was collected every $12 \mathrm{hrs}$ for $48 \mathrm{hrs}$ total for later plaque assay to analyze infectious virus produced from the cells. A low MOI was used here and in all experiments in order to see logarithmic growth of the viruses and to assess the effect of viral replication on host factors over a period of time.

LCMV replication kinetics were first determined in RAW 264.7 macrophages (Figure 1A). As shown in Figure 1A, both strains of LCMV infected 
A

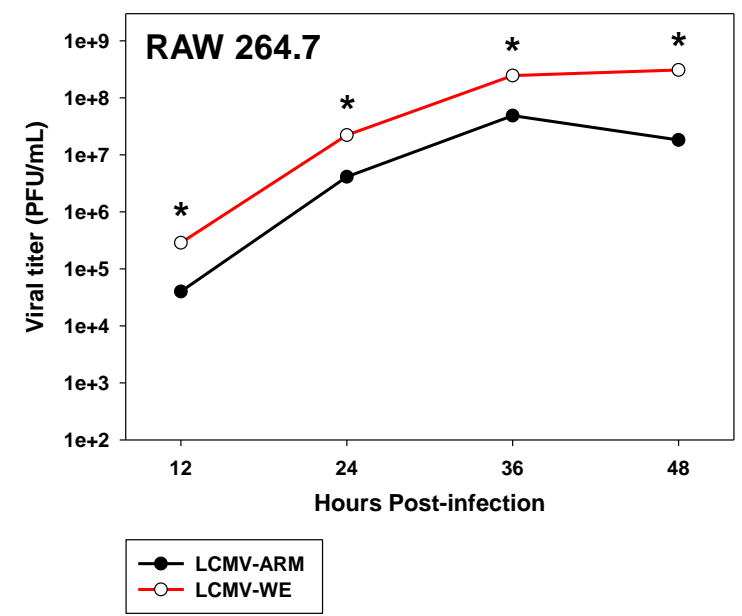

B

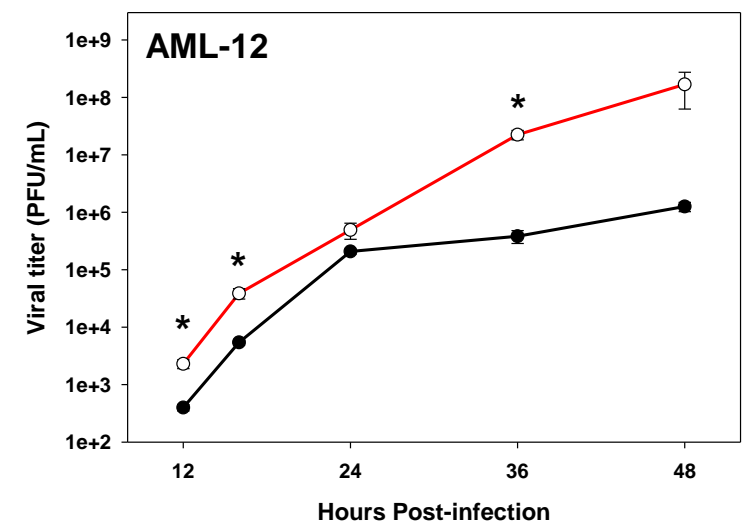

Figure 1. LCMV infects and replicates efficiently in RAW 264.7 macrophages and AML-12 hepatocytes. (A) RAW 264.7 and (B) AML-12 were infected with LCMV-WE or LCMV-ARM at $0.1 \mathrm{MOI}$ and supernatants were examined for productive viral replication by plaque titration assay, as described in Materials and Methods. Limit of detection for viral titer measurement is 100 $\mathrm{PFU} / \mathrm{mL}$. Data presented as means \pm S.E.M of technical replicates, $n=3$. *, indicates significance $(P<0.05)$, using Student's t-Test, between LCMV-WE and LCMV-ARM. 
and replicated efficiently in RAW 264.7 macrophages. Growth kinetics of viral replication from 12-48 hours post-infection (hpi) showed LCMV-WE replicated to significantly higher titers than LCMV-ARM at each time point. While both viruses replicated well in these cells, LCMV-WE did so more efficiently, reaching peak viral titers greater than 10-fold higher than those of LCMV-ARM at $36 \mathrm{hpi}$ and later. These growth kinetics results demonstrate that both LCMV-WE and LCMV-ARM infect and replicate in RAW 264.7 macrophages, with LCMV-WE replicating to higher titers than LCMV-ARM consistently throughout infection.

As mentioned above, hepatocytes are also important targets of arenavirus infection, following initial infection in KCs. To further investigate the role hepatocytes play in arenavirus-induced liver pathology, we next determined replication kinetics in AML-12 hepatocytes, using similar conditions and timing as those described above for RAW 264.7 infection with LCMV. As shown in Figure 1B, both LCMV-WE and LCMV-ARM replicated efficiently in AML-12 hepatocytes, with both strains reaching peak viral titers at $48 \mathrm{hpi}$. LCMV-WE replicated to significantly higher viral titers compared to LCMV-ARM, about 10fold higher early in infection (12, 16 hpi) and 100-fold higher late in infection (36 hpi). These growth kinetics data demonstrated AML-12 hepatocytes were permissive to both LCMV strains and though both LCMV-WE and LCMV-ARM replicated productively in these cells, LCMV-WE reached significantly higher titers than LCMV-ARM.

Thus, LCMV growth kinetics in RAW 264.7 macrophages and AML-12 hepatocytes revealed differences between LCMV-WE and LCMV-ARM's ability to 
replicate in these murine in vitro conditions. The next experiments focused on determining the impact of these differences in replication abilities on important host factors, like pro-inflammatory cytokines involved in hepatocyte proliferation.

\section{Highly productive replication of LCMV-WE in RAW 264.7 macrophages is associated with induction of pro-inflammatory cytokines.}

Since RAW 264.7 macrophages were indeed permissive to LCMV, we next examined the impact of LCMV infection on pro-inflammatory cytokines involved in triggering hepatocyte proliferation, TNF- $\alpha$ and IL-6. Cells from LCMVinfected RAW 264.7 macrophages were collected at the indicated times postinfection and analyzed for gene expression changes in TNF- $\alpha$ and IL-6 (Figure 2A). Fold mRNA induction of these genes was normalized to Gapdh (endogenous control) and relative to mock-infected (negative control). The relative mRNA levels of Tnf and II-6 were significantly increased during LCMVWE infection at 36 and $48 \mathrm{hpi}$, when compared to levels observed in LCMV-ARM infection. At these times, respectively, LCMV-WE induced Tnf expression 25and 15-fold over mock-infected cells, with LCMV-ARM modestly inducing Tnf at 5- and 3-fold over mock-infected cells. As seen in Figure 2A, II-6 expression was upregulated 80 -fold greater than mock-infected at 36 hpi and robust II-6 upregulation was observed at 48 hpi in LCMV-WE-infected cells, exhibiting levels >2000- fold over mock-infected cells. The effect of LCMV-ARM infection on II-6 expression at these time points was mild and significantly less than that of LCMV-WE. Robust differences in Tnf and II-6 gene expression at 36 and $48 \mathrm{hpi}$ 
A
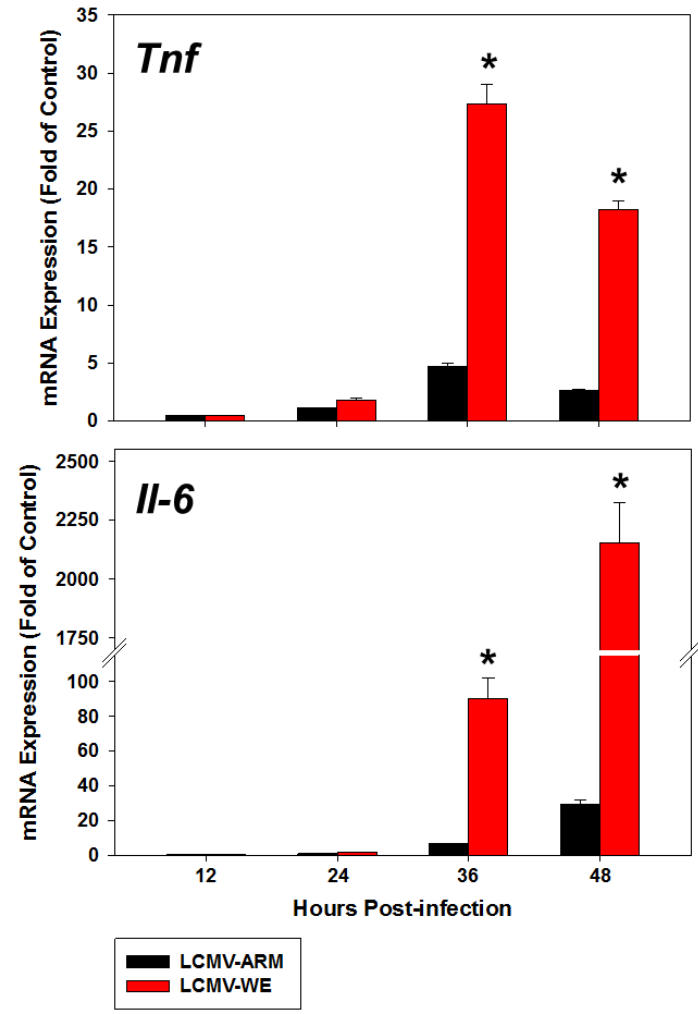

B

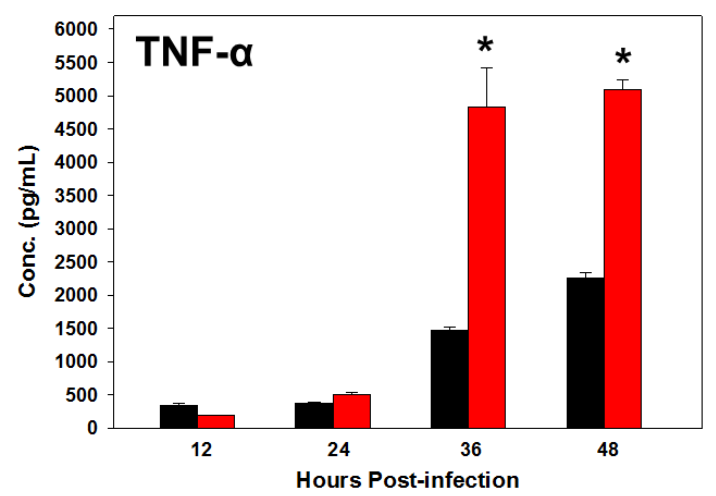

Figure 2. Highly productive replication of LCMV-WE in RAW 264.7 macrophages is associated with induction of pro-inflammatory cytokines.

RAW 264.7 were infected with LCMV-WE (red bars) or LCMV-ARM (black bars) at $0.1 \mathrm{MOI}$. (A) Cells were collected at indicated times for RNA isolation. cDNA was made and analyzed for pro-inflammatory cytokines, TNF and IL-6, using real-time RT-PCR. mRNA levels were graphed as fold mRNA normalized to Gapdh endogenous control and relative to mock-infected negative controls (not shown, but are equal to 1 -fold), as described in Materials and Methods. (B) Supernatants were collected at indicated times to evaluate murine TNF- $\alpha$ protein released from RAW 264.7 cells. A sandwich ELISA kit (R\&D Systems) was used to detect TNF- $\alpha$ protein concentration following manufacturer's instructions. Data presented as means \pm S.E.M of technical replicates, $n=3$. ${ }^{*}$, indicates significance $(P<0.05)$, using Student's t-Test, between LCMV-WE and LCMV-ARM. 
also correlated with LCMV-WE peak viral titers, which were greater than 10-fold over LCMV-ARM titers (Figure 1A).

Furthermore, to determine if these mRNA expression changes translated to TNF- $\alpha$ protein production, we tested supernatant media from each time point using an ELISA to detect and quantitate TNF- $\alpha$ released from RAW 264.7 macrophages (Figure 2B). We focused on TNF- $\alpha$ specifically because this proinflammatory cytokine was upregulated in our results from LCMV-WE infection in mice [45]; therefore, we focused on this cytokine in our murine macrophages here. As observed in Figure 2B, LCMV-WE-infected cells produced significantly greater concentrations of TNF- $\alpha$ protein $(>4500 \mathrm{pg} / \mathrm{mL})$ at 36 and 48 hpi about 3.5-fold greater than TNF- $\alpha$ produced from cells infected with LCMV-ARM ( $<2300 \mathrm{pg} / \mathrm{mL})$. Increases in levels of Tnf mRNA in LCMV-WE-infected cells at 36 and 48 hpi (Figure 2A) were thus confirmed at protein level with significant increases in TNF- $\alpha$ also produced from these LCMV-WE-infected cells. However, it was interesting that pronounced differences in TNF- $\alpha$ mRNA induction between LCMV-WE and LCMV-ARM-infected cells (e.g. 5-fold difference at $36 \mathrm{hpi}$ ) resulted in more subtle, but still obvious, differences in TNFa protein expression. In summary, these results demonstrate that LCMV-WE infection induced pro-inflammatory cytokines, TNF- $\alpha$ and II-6, which cytokine induction was also associated with peak LCMV-WE titers in RAW 264.7 macrophages. 


\section{TNF- $\alpha$ induces proliferation without affecting cell viability in growth- arrested, confluent AML-12 hepatocytes.}

TNF- $\alpha$ is a pleiotropic cytokine responsible for diverse biological effects in the liver, including apoptosis, survival, and proliferation [68]. One critical role of TNF- $\alpha$ in the liver, along with IL-6, upon release from KCs is its early involvement in triggering hepatocyte proliferation $[55,56,60]$. In the remaining in vitro experiments, we used a supra-physiological concentration of TNF- $\alpha$ at 200 $\mathrm{ng} / \mathrm{mL}$ to stimulate proliferation of confluent and growth-arrested AML-12 hepatocytes, modified protocol from [70, 73]. This concentration of TNF- $\alpha$, however, is greater than our observations of TNF- $\alpha$ produced by LCMV-WEinfected RAW 264.7 macrophages (Figure 2B).

TNF- $\alpha$ can have cytotoxic effects on cells. We first examined AML-12 cell viability to determine the effect of synchronizing cells in cycle for 2 days in low serum media per [70] and also the effect of TNF- $\alpha$ on the AML-12 cell viability. Cell viability was assessed by using an assay to quantitate ATP production (Figure 3A). Using the same protocol (modified from [70]) for the remaining experiments, AML-12 hepatocytes were seeded at confluency and subsequently growth-arrested for 2 days in low-serum 0.5\% FBS media. Following growtharrest was a 4 hour TNF- $\alpha$ stimulation to prime the cells to receive subsequent $5 \%$ FBS media, and cells were incubated in this media for 36 hours to test cell viability for the same length of time as later infection experiments lasted. These confluent, growth-arrested cells in $0.5 \%$ FBS were considered the baseline, as $100 \%$ viable (dotted line in Figure $3 \mathrm{~A}$ ). All other cell conditions were compared 
B
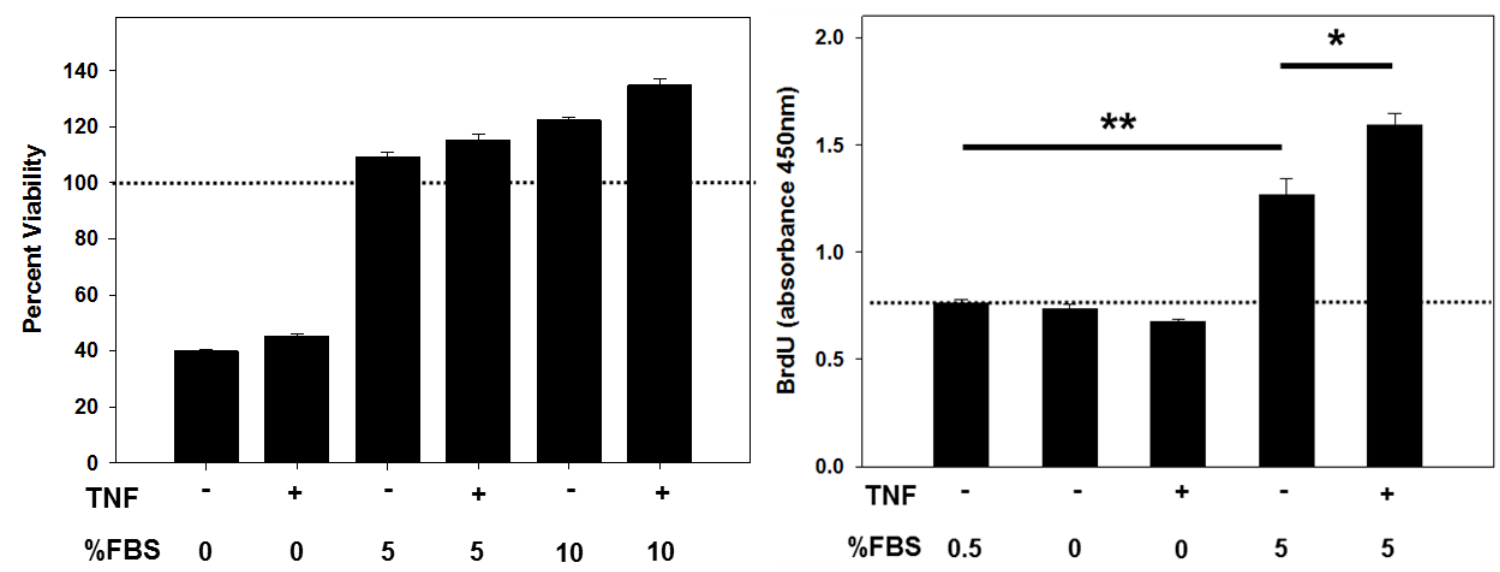

Figure 3. TNF- $\alpha$ induces proliferation without affecting cell viability in growth-arrested, confluent AML-12 hepatocytes. Cells were seeded at confluency, $4 \times 10^{4}$ cells/well of a 96 -well plate, cultured for $1 \mathrm{~d}$, and then changed to $0.5 \%$ FBS media to growth-arrest cells for $2 \mathrm{~d}$. Cells were stimulated with 200 $\mathrm{ng} / \mathrm{mL}$ TNF for $4 \mathrm{hrs}$ and then incubated in differing \%FBS media. (A) After 36hrs, AML-12 cell viability was measured with Cell Titer Glo assay (Promega). (B) After 20hrs, cell proliferation was determined using a kit (Cell Signaling Technology). BrdU was added to AML-12 to incorporate for 4hrs and then supernatant media removed and cells fixed/denatured. Cell proliferation was determined by amount of BrdU incorporation into cellular DNA via immuno-detection techniques and quantitating color change. Data presented as means \pm S.E.M of technical replicates, $n=4$. *, indicates significance $(P<0.05)$ between no TNF, 5\% FBS and TNF plus $5 \%$ FBS; ${ }^{* *}$, indicates significance $(P<0.05)$ between no TNF, $0.5 \%$ FBS and no TNF, 5\% FBS; using Student's t-Test. 
to the viability of these cells, because all $A M L-12$ experiments follow this same protocol. As determined from cell viability data in Figure 3A, regardless of TNF treatment, cells that were not released in serum media (the first two bars in the graph) showed signs of substantial cell death with $50 \%$ less viability than growtharrested cells. However, the cells released in either $5 \%$ or $10 \%$ FBS media with or without TNF stimulation (last four bars in Figure $3 \mathrm{~A}$ ) showed greater cell viability than the growth-arrested cells. It is evident from these analyses that growth-arresting and stimulating AML-12 hepatocytes with TNF- $\alpha$ does not cause cytotoxicity.

Next, the ability of TNF- $\alpha$ to induce hepatocyte proliferation in these confluent and growth-arrested AML-12 hepatocytes was determined (Figure 3B). AML-12 hepatocytes were seeded under the same conditions as the protocol described above. Growth-arrested cells were stimulated with TNF- $\alpha(200 \mathrm{ng} / \mathrm{mL})$ to prime the hepatocytes, followed by 24 hour incubation in 5\% FBS media containing TNF- $\alpha$. Proliferation was assessed via the number of cells in S phase of cell cycle, which was determined using an assay that measured BrdU incorporation into cells' newly synthesized DNA. As shown with the first bar in Figure $3 \mathrm{~B}$, the cells growth-arrested or synchronized in $0.5 \%$ FBS for 2 days (baseline), displayed minimal BrdU incorporation, thus minimal cell cycling activity. Cells that were not released in serum media showed similar or less BrdU incorporation, regardless of TNF stimulation. Released cells in 5\% FBS media with no TNF stimulation, however, showed significantly more BrdU incorporation than the synchronized AML-12 hepatocytes. Furthermore, AML-12 
hepatocytes released in 5\% FBS media and stimulated with TNF resulted in a significant increase in BrdU incorporation compared to cells synchronized in $0.5 \%$ media and also compared to cells receiving no TNF, but incubated in $5 \%$ FBS media. Thus, TNF stimulation with release in 5\% FBS media induced more proliferation than any other condition. Altogether, these data showed that TNF- $\alpha$ triggered AML-12 hepatocyte proliferation into $S$ phase, without toxicity to the cells.

\section{TNF- $\alpha$ enhances LCMV-WE replication in AML-12 hepatocytes.}

After finding that TNF- $\alpha$ is robustly produced from LCMV-WE infected macrophages (Figure 2), and TNF- $\alpha$ triggers AML-12 hepatocytes to proliferate without killing the cells (Figure 3), next we examined the impact of TNF- $\alpha$ on LCMV infection in AML-12 hepatocytes.

First, the ability of TNF- $\alpha$ to cause virucidal or inhibitory effects on LCMV-WE and LCMV-ARM was determined. LCMV-WE and LCMV-ARM virus stocks were incubated with TNF- $\alpha$ at high $(800 \mathrm{ng} / \mathrm{mL})$ and low $(12.5 \mathrm{ng} / \mathrm{mL})$ concentrations for 1 hour at $37^{\circ} \mathrm{C}$ and then plaque assay was used to assess viral titers. Virucidal effect was not detected at high or low TNF- $\alpha$ concentrations with either LCMV strain, as titers were unchanged with the addition of TNF- $\alpha$ (data not shown).

Confluent, synchronized AML-12 hepatocytes were stimulated with TNF- $\alpha$ and infected with LCMV to next determine if TNF- $\alpha$ had an impact on LCMV titers at one time point, $24 \mathrm{hpi}$. As observed with data shown in Figure 4A, cells 
A

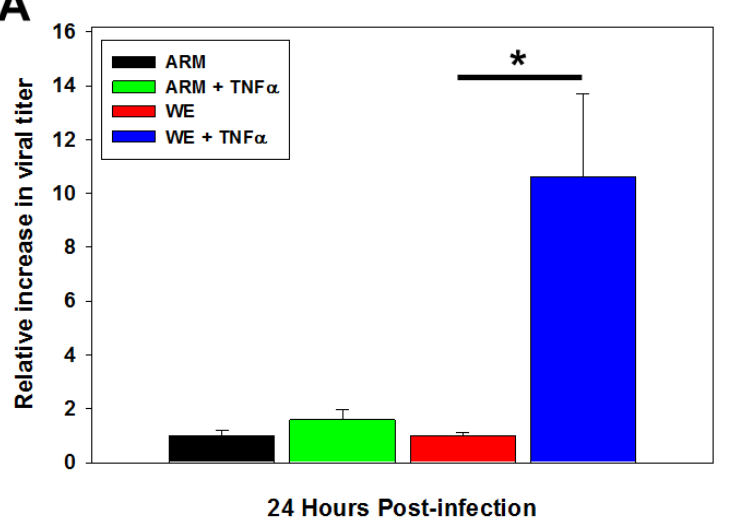

B
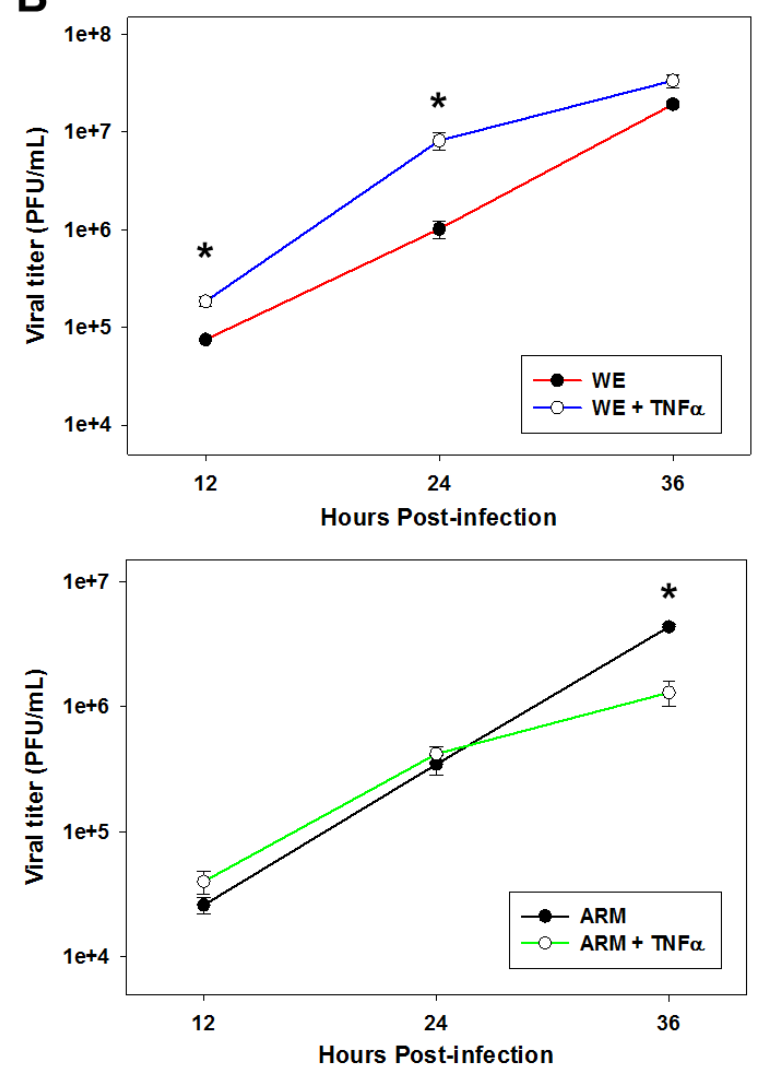

Figure 4. TNF- $\alpha$ enhances LCMV-WE replication in AML-12 hepatocytes. Confluent, growth-arrested AML-12 hepatocytes were stimulated with TNF- $\alpha$ $(200 \mathrm{ng} / \mathrm{mL})$ before infection and the cells were incubated in 5\% FBS media containing TNF- $\alpha$ after infection. (A) At $24 \mathrm{hpi}$, supernatants were collected and analyzed by plaque assay for quantitation of infectious virus production and viral titers were determined. LCMV-ARM and LCMV-WE titers produced from TNF- $\alpha-$ stimulated cells were normalized to LCMV-ARM and LCMV-WE titers, respectively, produced from unstimulated cell. LCMV titers from unstimulated cells were considered $=1$ and relative increases in LCMV titers with TNF- $\alpha$ stimulation were quantitated relative to 1 . (B) At 12, 24, and 36 hpi supernatants were collected and analyzed by plaque assay for quantitation of infectious virus production. Data presented as means \pm S.E.M of technical replicates, $n=3$. *, indicates significance $(P<0.05)$, using Student's t-Test, between WE and WE + TNF- $\alpha$; or, ARM and ARM + TNF- $\alpha$. 
stimulated with TNF- $\alpha$ and infected with LCMV-WE produced significantly greater viral titers, more than 10-fold higher compared to titers produced from LCMV-WE infection without TNF- $\alpha$. However, with or without TNF- $\alpha$ stimulation of AML-12 hepatocytes, LCMV-ARM titers were unchanged at $24 \mathrm{hpi}$. Thus, TNF- $\alpha$ had a significant impact on LCMV-WE titers at one time point, enhancing titers greater than 10 -fold.

Next, we assessed the impact of TNF- $\alpha$ on viral replication over a 36 hour time period when exponential viral replication occurs, at 12, 24, and $36 \mathrm{hpi}$, in AML-12 hepatocytes. As observed in Figure 4B, in cells stimulated with TNF-a, LCMV-WE replicated to significantly higher viral titers early in infection at 12 and $24 \mathrm{hpi}$, compared to titers found with LCMV-WE infection alone. By $36 \mathrm{hpi}$, LCMV-WE was reaching peak titers in TNF- $\alpha$ stimulated cells. However, in unstimulated cells, LCMV-WE kinetics were continuing to displaying exponential replication from 24 to 36 hpi. Analysis of LCMV-ARM replication with TNF- $\alpha$ stimulation in the bottom graph of Figure 4B, showed that regardless of TNF- $\alpha$ stimulation, similar titers were observed for LCMV-ARM from 12 to 24 hpi. By 36 hpi, however, LCMV-ARM titers continued to grow reaching significantly higher titers than those observed in TNF-a-stimulated cells. Thus, with the addition of TNF- $\alpha$, LCMV-ARM replicated similarly to LCMV-ARM alone, until late in infection. Yet, the addition of TNF- $\alpha$ with LCMV-WE resulted in more efficient replication and enhanced viral titers compared to LCMV-WE without TNF- $\alpha$. These results suggest TNF- $\alpha$ stimulation of AML-12 hepatocytes, which we 
showed induces proliferation (Figure 3B), also promotes LCMV-WE viral replication.

\section{TNF- $\alpha$ stimulation with LCMV-WE infection induces $G_{1} / S$ phase cell cycle mediators and non-conventional receptor in AML-12 hepatocytes}

Arenaviruses like LASV and LCMV-WE cause severe infections characterized by an induction of pathological hepatocyte proliferation, which is an exaggerated, pathological response in view of the mild damage caused by these viruses [26, 29, 30, 42, 45]. Furthermore, liver hyperplasia was not evident in human LF cases nor in NHP or murine animal models of LF-like disease, suggesting hepatocyte cell cycle is incomplete [25, 26, 45]. Thus, we next investigated the effect of LCMV infection on cell cycle mediators in our proliferating AML-12 hepatocytes.

Using TNF- $\alpha$ stimulation to induce hepatocyte proliferation in AML-12 hepatocytes (data shown in Figure 3B), cell cycle mediators involved in regulating $\mathrm{G}_{1} / \mathrm{S}$ phase progression were assessed after LCMV infection (Figure 5). Gene expression changes in cell cycle mediators were examined using RTPCR analysis, with fold mRNA induction normalized to Gapdh (endogenous control) and relative to mock-infected (negative control). As seen in Figure 5A, cyclin-dependent kinase 6 (Cdk6) and cyclin D, important regulators of cell cycle progression at $G_{1}$ to $S$ phase, were examined first. TNF- $\alpha$ stimulation without virus in AML-12 hepatocytes, the positive control condition for active cell cycle, resulted in a modest 2-fold increase in Cdk6 mRNA at $36 \mathrm{hpi}$, but cyclin D levels 

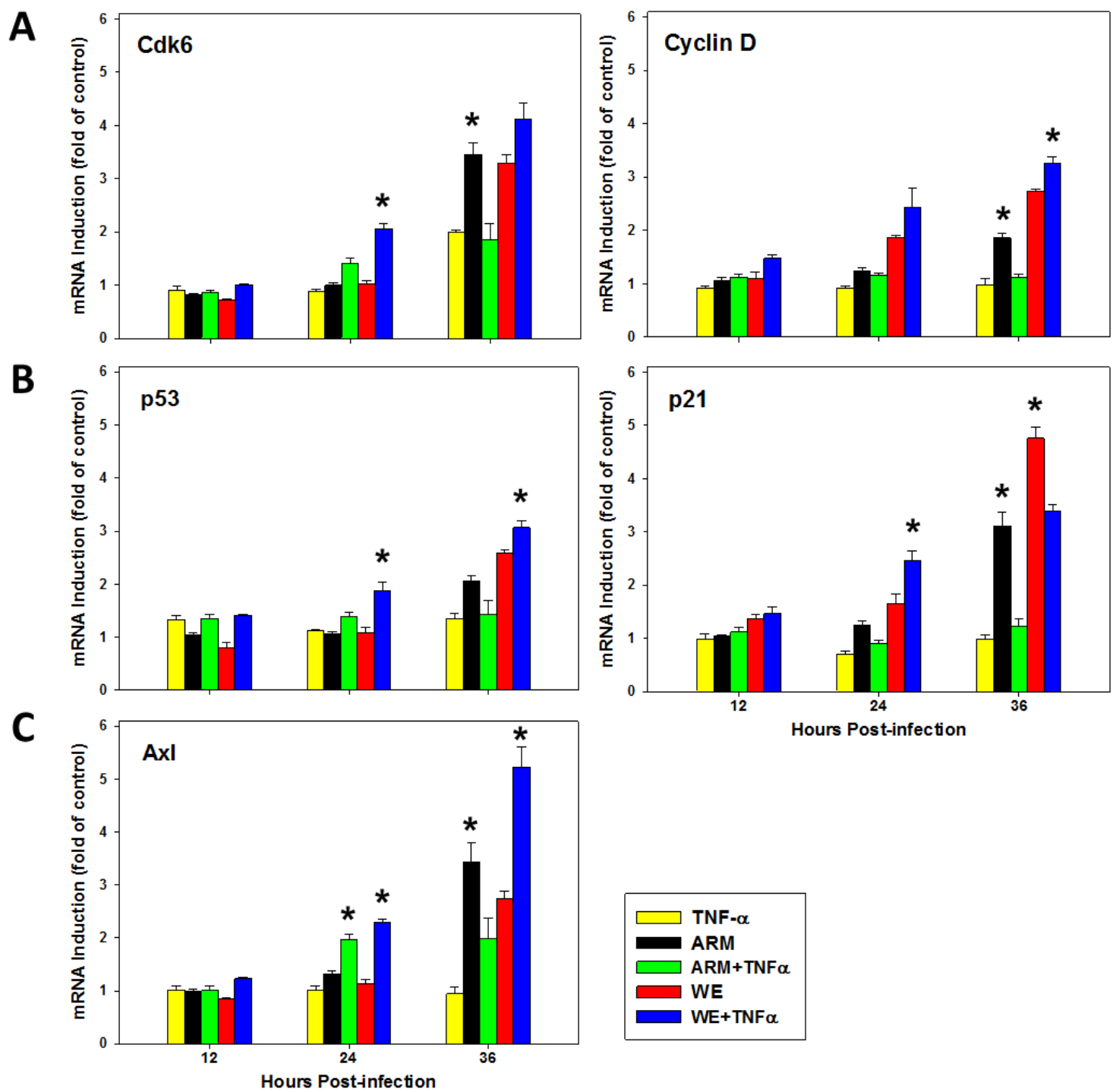

Figure 5. TNF- $\alpha$ stimulation with LCMV-WE infection induces $\mathrm{G}_{1} / \mathrm{S}$ phase cell cycle mediators and non-conventional receptor in AML-12 hepatocytes. Growth-arrested AML-12 were stimulated with TNF- $\alpha(200 \mathrm{ng} / \mathrm{mL})$ and infected with LCMV-WE or LCMV-ARM at $0.1 \mathrm{MOI}$ for $1 \mathrm{hr}$ at $37^{\circ} \mathrm{C}$. Cells were washed and incubated in 5\% FBS media containing TNF- $\alpha$ until termination at the indicated hpi. Cells were collected at indicated times for RNA isolation. cDNA was made and analyzed for cyclin D and Cdk6 (A), p53 and p21 (B), and Axl receptor $(C)$ using real-time RT-PCR. mRNA levels were graphed as fold mRNA normalized to Gapdh endogenous control and relative to mock-infected negative controls (not shown, but are equal to 1-fold), as described in Materials and Methods. Data presented as means \pm S.E.M of technical replicates, $n=3$. *, indicates significance $(P<0.05)$, between ARM and ARM + TNF- $\alpha$, or WE and WE + TNF-a, using Student's t-Test. 
were unchanged and similar to mock-infected controls at each time point. Upregulation of both Cdk6 and cyclin D mRNA was, however, observed with the addition of LCMV-ARM infection, with most significant changes occurring at 36 hpi with 4- and 2-fold upregulation, respectively, of these genes. Interestingly, when TNF- $\alpha$ was added to LCMV-ARM infection, mRNA levels of both Cdk6 and cyclin D at 36 hpi were reduced closer to background levels of controls. Generally, LCMV-WE infection, induced gene expression of both cell cycle regulators close to 3 -fold over control conditions by $36 \mathrm{hpi}$. With the addition of TNF- $\alpha$ to LCMV-WE infection, however, Cdk6 levels were similar and cyclin D levels were significantly higher than those mRNA levels with LCMV-WE infection alone. Furthermore, induction of both Cdk6 and cyclin D at 36 hpi was also associated with peak viral titers for LCMV-WE with and without TNF- $\alpha$ and for LCMV-ARM infection alone (Figure 4B). To summarize, these gene expression data suggest $L C M V$ infection induces $G_{1}$ cell cycle regulators; however, with the addition of TNF- $\alpha$ to LCMV infection revealed stark differences in LCMV-ARM versus LCMV-WE to induce these cell cycle regulators.

We next examined $\mathrm{G}_{1}$ cell cycle progression with TNF- $\alpha$ stimulation and LCMV infection in AML-12 hepatocytes by analyzing gene expression of p53 and p21 cell cycle inhibitors (Figure 5B). TNF- $\alpha$ stimulation without virus infection showed similar p53 and p21 gene expression profiles as that found with mockinfected controls. As observed in Figure 5B, LCMV-ARM infection, with or without TNF- $\alpha$ stimulation, did not significantly alter levels of p53. In contrast, LCMV-WE infection induced p53 mRNA, especially at $36 \mathrm{hpi}$. However, with 
TNF- $\alpha$, LCMV-WE significantly induced p53 levels at 24 and 36 hpi compared to LCMV-WE infection alone. Furthermore, p21 mRNA levels were significantly induced with LCMV-ARM infection alone at 36 hpi 2-fold over LCMV-ARM with TNF- $\alpha$ and 3-fold over mock-infection controls. This induction was not found with LCMV-ARM and TNF- $\alpha$ stimulation at $36 \mathrm{hpi}$, as p21 levels were unchanged compared to mock-infected control. With LCMV-WE infection alone, p21 mRNA was robustly induced at 36 hpi 5-fold over control cells, which was significantly (i.e. 1.5-fold) greater than p21 induction observed with TNF- $\alpha$ and LCMV-WE infection. Though this p21 induction with TNF- $\alpha$ and LCMV-WE infection was less than that observed with LCMV-WE alone, p21 levels were still over 3-fold greater than levels in control conditions. Thus, TNF- $\alpha$ stimulation with LCMV-WE only minimally reduced p21 levels; while, TNF- $\alpha$ stimulation with LCMV-ARM considerably reduced p21 closer to background, control levels. Overall, these data demonstrated evidence of $\mathrm{G}_{1} / \mathrm{S}$ phase cell cycle arrest with upregulation of p21 inhibitor in LCMV-WE-infected cells regardless of TNF- $\alpha$ stimulation and this p21 upregulation was also associated with high levels of LCMV-WE viral replication.

We also looked at gene expression of $\mathrm{Axl}$, a receptor tyrosine kinase and non-conventional receptor for LCMV and LASV entry into host cells [74]. Our recent studies showed $A x l$ to be upregulated at the gene and protein expression levels in the liver of LCMV-WE-infected mice [45]. As a potential viral entry factor into hepatocytes and a key player involved in inhibiting TLR-immune responses 
[75], we examined the impact of TNF- $\alpha$ and LCMV infection on gene expression of $A x l$ in $A M L-12$ hepatocytes (Figure $5 C$ ).

Similar to its effects on cell cycle mediators' gene expression, TNF- $\alpha$ stimulation alone without virus infection did not alter Axl gene expression and was similar to mock-infected controls, as shown in Figure 5C. LCMV-ARM infection alone only induced Axl mRNA at $36 \mathrm{hpi}$, which was 3-fold over controls and 1.5-fold greater than levels observed with LCMV-ARM and TNF- $\alpha$. Interestingly, LCMV-ARM with TNF- $\alpha$ induced AxI mRNA levels at 24 hpi 2-fold over controls and these levels were significantly greater than those found with LCMV-ARM alone. While LCMV-WE infection showed greater than 2-fold increases in Axl mRNA by 36 hpi, LCMV-WE with TNF- $\alpha$ stimulation robustly induced Axl levels earlier, 2-fold at $24 \mathrm{hpi}$, and later, 5-fold at $36 \mathrm{hpi}$, over controls. Thus, with TNF- $\alpha$, Axl levels were induced greater than 2.5 -fold with LCMV-WE infection compared to LCMV-WE infection alone by $36 \mathrm{hpi}$. Altogether, significant changes in Axl gene expression were found late in LCMV infection and most robust when TNF- $\alpha$ stimulation was coupled with LCMV-WE infection. These increases in Axl expression with LCMV-WE infection potentially suggest viral manipulation of host cell machinery to increase production of its receptor, thus increasing viral entry points into the cell.

\section{High viral load and upregulated pro-inflammatory IL-6 cytokine correlated with cell cycle arrest in livers of NHPs fatally-infected with LASV}


Finally, to correlate these in vitro findings regarding LCMV-WE-induced cell cycle arrest in AML-12 hepatocytes with an in vivo model, we examined liver tissue from NHPs (i.e. marmosets) fatally- and non-fatally-infected with LASV. We analyzed viral loads and gene expression profiles of liver tissue samples from non-fatal marmoset \#10 and fatal marmosets \#11 and \#12 for changes in IL-6, cyclin D, p53, p21, and AXL gene expression using RT-PCR (Figure 6).

Fatal LASV infection in diseased marmosets was characterized by high viral load in the livers of \#11 and \# 12, with over 10,000 copies of viral RNA per $\mu \mathrm{g}$ of tissue, as shown in Figure 6A. Furthermore, these high viral loads were also correlated with robust increases in pro-inflammatory cytokine IL-6, as liver tissue from \#11 showed over 800-fold mRNA induction over non-fatally-infected \#10. However, only mild IL-6 increases were observed for \#12 at 6-fold over control marmoset.

Cyclin D mRNA levels were examined in Figure 6B to look at the degree of hepatocyte proliferation, though this was not a complete assessment of proliferation. Liver tissue from \#12 showed moderate Cyclin D elevation at 5-fold over non-fatal marmoset \#10, but this increase was not observed in \#11, which showed expression similar to control \#10. We have already observed high viral load, robustly upregulated IL-6 and mild increases in Cyclin D levels, suggesting efficient viral replication, dysregulated liver function and pathological hepatocyte proliferation. Next we determined if these pathologies also correlated with evidence of incomplete cell cycle in the livers of fatal LASV infection-as we 

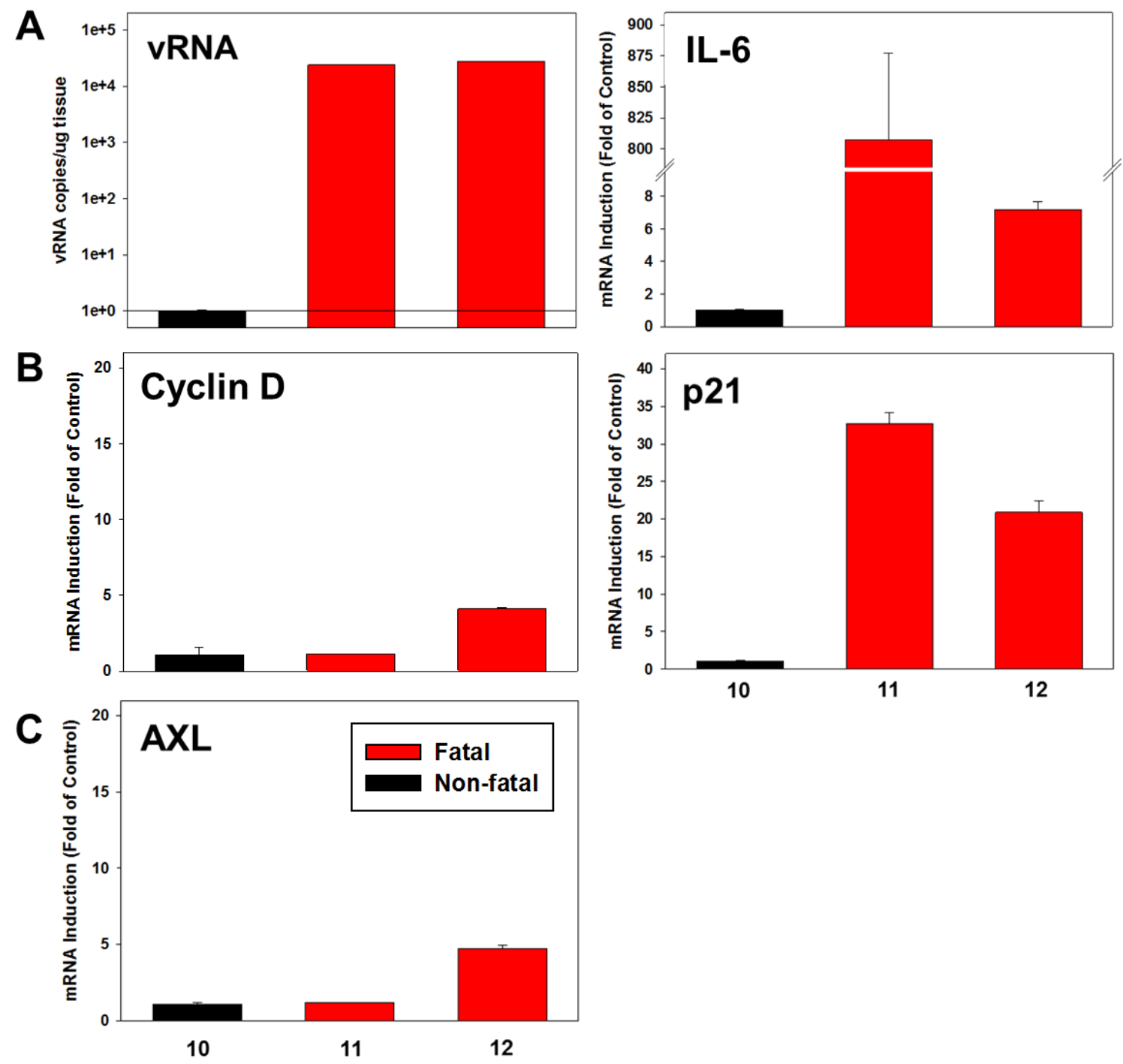

Figure 6. High viral load and upregulated pro-inflammatory IL-6 cytokine correlated with cell cycle arrest in livers of NHPs fatally-infected with LASV. Marmosets were challenged with LASV and marmoset \#10 survived (non-fatal) and \#'s 11 and 12 died (fatal). Liver tissues samples were analyzed for changes in mRNA levels using real-time RT-PCR. Gene expression levels were assessed for: (A) viral RNA and IL-6, (B) Cyclin D and p21, and (C) AXL. mRNA levels were normalized to $18 \mathrm{~S}$ endogenous control and relative to those of non-fatal marmoset \#10. Viral RNA was detected with primers specific to LASV-NP and all primers were purchased from Life Technologies. 
demonstrated with LCMV-WE in AML-12 hepatocytes (Figure 5B) and previously with LCMV-WE-infected mice [45]. Thus, gene expression of cell cycle inhibitor, p21, was characterized. Interestingly, as shown in Figure 6B, robust upregulation of p21, greater than 30 - and 20-fold, was observed in \#11 and \#12, respectively, over the expression found in $\# 10$ control. These results demonstrate cell cycle arrest and p21 play important roles in pathogenicity of fatal disease caused by LASV. These results also confirm the in vitro results we found here with LCMV-WE infection in AML-12 hepatocytes. In summary, high levels of viral RNA, pro-inflammatory IL-6, and robust increases in p21 were characteristic of liver tissue from fatal LASV infection in marmosets.

Lastly, we tested liver tissue for changes in gene expression of a nonconventional viral receptor, AXL. As shown in Figure 6C, liver tissue from \#12 showed elevated AXL expression, >4-fold higher than \#10 control. AXL expression in \#11 liver, however, displayed levels similar to control. AXL expression examined here did not show a clear trend in these fatally-infected liver tissue samples, though AXL may still play an important role in LASV and LCMV-WE pathogenic mechanisms within severe infections. 


\section{DISCUSSION}

Pathological hepatocyte proliferation and high viral load in liver tissue are associated with severe OW arenavirus (i.e. LASV and WE) infections. Thus, our overall objective was to examine the effect of arenavirus-induced hepatocyte proliferation on viral replication and cell cycle progression. To study this, we used well-studied cell lines, murine RAW 264.7 macrophages to represent KCs of the liver and murine AML-12 hepatocytes. LCMV-WE replicated efficiently in RAW 264.7 macrophages and led to significant induction of TNF- $\alpha$ and IL-6 proinflammatory cytokines. Next, TNF- $\alpha$ and its effect on nearby hepatocytes was analyzed and we found that TNF- $\alpha$-stimulated AML-12 hepatocytes infected with LCMV-WE resulted in enhanced viral replication compared to LCMV-WE infection alone. Significant enhancement of viral replication also correlated with induction of cell cycle mediators indicative of $\mathrm{G}_{1}$ phase and cell cycle arrest. Building on these in vitro findings and patterns previously noted in NHPs [26, 42] and mice [45], liver tissue taken from marmosets fatally infected with LASV also showed high viral load, robust induction of IL-6 mRNA, and active cell cycling with evidence of arrested cell cycle at $\mathrm{G}_{1} / \mathrm{S}$ phase.

Differences in replication kinetics and titers between LCMV-WE and LCMV-ARM were characteristics of infection in murine macrophages and hepatocytes (Figure 1). These replication differences between LCMV-WE and 
LCMV-ARM have been noted in different in vitro cell models used in this lab and are also highly repeatable. Several reasons for replication differences between LCMV-WE and LCMV-ARM are possible. LCMV has been extensively studied in research settings. The LCMV-ARM strain was passed through experimental mice many times and thus, is well-adapted to mice and considered the neurotropic strain (targets nerve cells). However, LCMV-WE is considered the viscerotropic strain, targeting macrophages, dendritic cells, and endothelial cells, among others, for infection in host tissues. It is reasonable that LCMV-WE is able to more efficiently replicate in tissue cells like hepatocytes. Furthermore, LCMV-WE and LCMV-ARM share $84 \%$ and $91 \%$ homology at the nucleotide and amino acid sequence levels [39]. However, these viruses differ in pathogenic potential, and in affinity for cellular receptor [76]. Differences in affinity for cellular receptor to enter host cell also can provide an explanation of differences in replication kinetics. While use of $\alpha-D G$ is the preferred method of host entry for the virus, research has shown LCMV strains have varying affinities for $\alpha$-DG. LCMV-WE (WE 54), the pathogenic strain, for example, displays higher affinity for $\alpha$-DG than the non-pathogenic strain, LCMV-ARM, which demonstrates low affinity [76]. Similarly, LASV GP1 has 2 logs higher affinity to a-DG in comparison with LCMV-ARM. Thus, it is possible that LCMV-WE is entering the host cell more quickly because it binds the receptor with greater affinity, is internalized more quickly, and thus LCMV-WE may have a "head-start" in replicating too. 
It is well-documented that OW arenavirus infection, like fatal LASV, characteristically evades detection and suppresses innate and adaptive immune responses, reviewed in [4]. This is contrary to the "cytokine-storm" prompted by filoviruses like Ebola virus or by NW arenavirus Junin virus, reviewed in [4]. Studies on LF disease in humans and on NHPs experimentally-infected with LASV or LCMV-WE have shown a late-stage, pro-inflammatory profile with severe infections, which highlights IL-6 as a biomarker in terminal disease stages $[26,27,43,53]$ and it is also shown in early disease development [43]. Thus, in vivo, pro-inflammatory cytokine profiles differ depending on stage of disease and clinical outcome of disease. However, our in vitro results shown here (Figure 1A, Figure 2) that replication of LCMV-WE induced TNF- $\alpha$ and IL-6 mRNA. These results differ from previous in vitro studies that support an immunosuppressive phenotype of pathogenic OW arenavirus infections in human monocyte-derived macrophages. For example, it was demonstrated that productive LASV and LCMV-WE infections resulted in suppressed proinflammatory responses (i.e. IL6, TNF- $\alpha$, or IL-8), while non-pathogenic arenaviruses, MOPV and LCMV-ARM, showed an upregulation of proinflammatory response [22, 26, 62, 63]. Pathogenic OW arenaviruses do not activate macrophages [63], and LASV, LCMV-WE, and Clone 13 (immunosuppressive derivative of LCMV-ARM strain) were shown to inhibit the TLR2/Mal-dependent production of cytokines that the non-pathogenic LCMV-ARM and MOPV did in fact stimulate with productive replication [62]. Therefore, in vitro data regarding pro-inflammatory response induced by pathogenic OW arenaviruses seem to differ according to cell species 
used (e.g. human versus murine), the techniques or assays used for analysis, and also parameters of experiments and what hypotheses were used to guide experiments.

Though these results are at-odds with our current findings that show LCMV-WE replication is associated with both IL-6 and TNF- $\alpha$ production, it is potentially explainable by the use of different cell types-we used murine cells and previous studies used human cells. Differences between the responses of murine and human/NHP immune systems are exemplified in the unexpected proinflammatory results from the livers of LCMV-WE experimentally-infected mice [45]. IL-6 was expected to be robustly up-regulated, as it was in NHPs liver tissue and plasma with severe LCMV-WE infection. Instead, IL-6 was mildly upregulated and TNF- $\alpha$ pro-inflammatory mediator was robustly induced, which also was associated with characteristic OW arenavirus-induced liver pathology of spotty necrosis, pathological hepatocyte proliferation, and increased viral replication [45]. Furthermore, it is important to highlight that LCMV's natural reservoir host is Mus musculus, the house mouse. It has co-evolved with this host and its immune system causing low level infection without inducing disease in the mouse. Therefore, it is reasonable to conclude that the pro-inflammatory cytokines resulting from LCMV infection in its host may not align with the profiles observed in NHPs or in humans with LASV infection.

Building on the TNF- $\alpha$ cytokine response observed from LCMV-WE infection in RAW 264.7 macrophages, we used this virus-induced TNF- $\alpha$ signal to stimulate hepatocyte proliferation in vitro and then look at the impact of actively 
cycling hepatocytes on LCMV-WE's replication kinetics. This two-hit model was set-up to mimic and investigate the liver pathologies caused by OW arenaviruses. Two-hit experimental models are commonly employed in liver research to study mechanisms of injury and oftentimes include LPS as a second hit to exacerbate damage from a first hit (e.g. alcohol, high-fat diet, high-dose toxins, etc.). Furthermore, models of liver regeneration have shown support for enteric LPS being the stimulus for KCs to produce pro-inflammatory triggers (i.e. TNF- $\alpha$ and IL-6) involved in prompting hepatocyte proliferation [58, 59]. However, both our in vitro research shown in this work and, as mentioned above, previous in vivo models have demonstrated high levels of these pro-inflammatory triggers of hepatocyte proliferation associated with robust pathological hepatocyte proliferation and high levels of OW arenavirus infection. More recently, Campbell et al. has provided evidence demonstrating that proinflammatory signals necessary for successful liver regeneration were dependent on MyD88 signaling pathway, and not on pathways downstream of Cd14, TLR2, and TLR4-the LPS receptor on KCs [61]. Research from this group has demonstrated in human macrophages that pathogenic OW arenaviruses like LASV and LCMV-WE inhibit TLR2/Mal-dependent pro-inflammatory cytokine responses, and non-pathogenic counterparts, MOPV and LCMV-ARM, enhanced these pro-inflammatory responses via this pathway [62]. Thus, it seems possible that different species, human versus murine, respond differently to the virus, especially considering that LCMV's reservoir host is a rodent, as mentioned above. Additionally, we also found robust increases in TNF- $\alpha$ and not IL-6 in liver 
tissue from LCMV-WE-infected mice [45], which is generally opposite to the proinflammatory profiles found in humans [53] and NHPs [26, 27] infected with pathogenic OW arenaviruses.

In the studies shown here, TNF- $\alpha$ stimulation of AML-12 cells results in enhanced LCMV-WE viral replication, while LCMV-ARM replication was unaffected by TNF- $\alpha$ (Figure 4B). TNF- $\alpha$ is a pleiotropic cytokine responsible for diverse biological effects in the liver, including apoptosis, survival, and proliferation [68]. One critical role of TNF- $\alpha$ in the liver, along with IL-6, upon release from $\mathrm{KCs}$ is its early involvement in triggering hepatocyte proliferation $[55,56,60]$. TNF- $\alpha$ can cause toxicity and cell death in high concentrations, reviewed in $[64,65]$. In the in vitro experiments shown in this thesis, we used a supra-physiological concentration of TNF- $\alpha$ at $200 \mathrm{ng} / \mathrm{mL}$ to obtain a maximized effect on the confluent and growth-arrested conditions of the AML-12 hepatocytes used in these experiments. Though, it has been shown that 20 $\mathrm{ng} / \mathrm{mL}$ TNF- $\alpha$ treatment in hepatic in vitro cells can induce DNA synthesis [70, 73]. We modified these protocols using a higher TNF- $\alpha$ concentration, which, however, is higher than that produced by LCMV-WE-infected RAW 264.7 macrophages. Furthermore, Fletcher et al. showed that with increasing concentrations of TNF- $\alpha$ (i.e. $10,100,1000 \mathrm{ng} / \mathrm{mL}$ ) there was a correlated TNFdependent increase in hepatitis c virus (HCV) and LASV-psuedotyped-particle virus infectivity in polarized HepG2 [77]. However, another group using Huh7 human hepatoma cells found TNF- $\alpha$ stimulation (at physiologically low concentration) alone or in combination with IFN did not positively or negatively 
impact replication of LASV or LCMV-WE [78]. Recently, a group showed enhanced LCMV-WE viral load in livers from mice experimentally-induced to develop inflammation via a murine hepatic ischemia/reperfusion model [79]. They concluded that inflammation resulting from TNF- $\alpha$ and LPS enhanced expression of the interferon stimulated gene (ISG) ubiquitin-like protease 18 (USP18) in hepatocytes, which was then associated with the enhanced replication of LCMVWE. Their proposed mechanism of enhanced replication is linked to increased expression of USP18, which disrupts hepatocytes' ability to respond to IFN- $\alpha$.

Cell cycle mediators of $G_{1}$ phase, cyclin $D$ and $C d k 6$, were upregulated in TNF- $\alpha$-stimulated and LCMV-WE-infected AML-12 hepatocytes. The $\mathrm{G}_{1}$ phase is rich in translational activity to produce proteins needed to prepare the cell for DNA synthesis in $S$ phase. This resource-rich environment could provide obvious benefits for replicating viruses in need of host cell machinery. Past in vitro data has shown LCMV infection can indeed impact cell cycling factors. HeLa cells transfected with the $Z$ protein of LCMV, resulted in decreased protein production of cyclins D and E [80]. Decreased D- and E-type cyclins results in a lack of progress through $\mathrm{G}_{1}$ phase to $S$ phase, which was evident in our findings with increases in p21, an indicator of cell cycle arrest. Furthermore, we did not examine protein levels of these cell cycle mediators or look at cyclin E, so it is unclear if our in vitro system would show similar decreases in protein levels. It was previously demonstrated that $\mathrm{PRH} / \mathrm{HEX}$, the proline-rich homeodomain protein or hematopoietically expressed homeobox, is down-regulated in human hepatoma cells (i.e. HepG2 and Huh7) and also in the livers of LCMV-WE- 
infected NHPs [81]. Under normal conditions, PRH/HEX functions in liver cells to resist proliferation, by blocking the activity of cell cycle mediators involved in $\mathrm{G}_{1}$ phase progress. This protein nor its gene expression was examined in our work, but it seems likely that a decrease in the $\mathrm{PRH} / \mathrm{HEX}$ protein would be noted early in the $G_{0}$ to $G_{1}$ phase of cell cycle when the cells come out of growth-arrest and begin to cycle.

Arenaviruses like LASV and LCMV-WE cause severe infections characterized by an induction of pathological hepatocyte proliferation, which is an exaggerated, pathological response in view of the mild damage caused by these viruses [26, 29, 30, 42, 45]. Furthermore, liver hyperplasia was not evident in human LF cases nor in NHP or murine animal models of LF-like disease, suggesting hepatocyte cell cycle is incomplete [25, 26, 45]. Furthermore, we recently showed that LCMV-WE infection in mice not only induced pathological hepatocyte proliferation, but robust increases in $\mathrm{G}_{1} / \mathrm{S}$ arrest marker, p21 were also observed at the mRNA and protein levels [45]. These results indicated, pathological hepatocyte proliferation was arrested via p21 cell cycle inhibitor at the $\mathrm{G}_{1}$ to $S$ phase transition. Results from this work with TNF- $\alpha$ stimulated and proliferating AML-12 hepatocytes infected with LCMV-WE showed increases in gene expression of cell cycle inhibitor, p2 (Figure 5B). This was also confirmed, robust p21 mRNA upregulation, in liver tissue from marmosets fatally-infected with LASV (Figure 6B). An important regulator of hepatocyte proliferation, p21 is controlled by p53-dependent and -independent mechanisms and can also be regulated by mitogens and growth factors $[82,83]$. Furthermore, IFNy could play 
a role in the strong induction of $\mathrm{p} 21$, as IFNy was also robustly upregulated in LCMV-WE-infected mice [45] and can signal to induce cell cycle arrest in the liver via p21, reviewed in [84]. p21, however, normally has a quick turnover rate in the cell (i.e. $t_{1 / 2}$ of $\sim 30 \mathrm{~min}$.), reviewed in [52], and our in vitro results showing high levels of mRNA induction, as well those mRNA levels observed in marmosets and mice, indicate that p21 is not being degraded, but potentially transcripts are being stabilized. Respiratory syncytial virus has been shown to cause $G_{1}$ cell cycle arrest to increase viral replication by a p53-dependent pathway, which also resulted in accumulation of p21 $[47,85]$. More extensive and focused in vitro research is required to determine the role of p21 and cell cycle arrest as a potential pathway to block and reduce infection.

Axl, an additional receptor for LASV and LCMV [74], was significantly upregulated in LCMV-WE-infected AML-12 hepatocytes stimulated with TNF- $\alpha$ (Figure 5C). We also showed in a surrogate model of LF hepatitis in mice infected with LCMV-WE that Axl was significantly upregulated at the mRNA and protein levels in liver tissue [45]. Furthermore, our in vitro findings here that showed elevated AxI mRNA levels with LCMV-WE infection were also confirmed in vivo in liver tissue of fatally-infected marmosets with LASV (Figure 6C). Together these data demonstrate that upregulation of $\mathrm{Axl}$ is a shared mechanism among pathogenic arenaviruses LASV and LCMV in vitro and in vivo. However, previous research by Sullivan et al. complicates this idea, as this group used LCMV Clone 13 infection in Axl knock-out mice and showed no difference in viral replication kinetics between Axl knock-out and wild-type mice and concluded that 
AxI was not needed for productive LCMV infection in mice [86]. While this group used a different LCMV strain than we used in our vitro and murine in vivo research, their research along with our results, could highlight that the upregulated $\mathrm{Axl}$ we have observed during LCMV infection is potentially an indirect effect of the virus and not directly used by the virus as a cellular receptor. Or it is possible that LCMV Clone 13 does not have the same affinity for Axl receptor as LCMV-WE or LASV, so it does not depend on this cellular receptor for host cell entry and replication. Axl, as a receptor tyrosine kinase, has many different roles in cells throughout the body, including cell-cell communication, survival, proliferation and regulation of immune response, reviewed in [87]. Increases in Axl expression could be a mechanism to promote viral replication in the liver, as Axl plays an important role in the liver (along with fellow Tyro3 and Mer receptors) in inhibiting TLR-mediated immune response [75] to maintain immune-tolerance [88]. As previous research has showed, Axl is also used by LASV and LCMV as an alternate receptor, besides the conventional receptor $\alpha$ dystroglycan [20], to enter host cells [74]. Thus, increasing Axl expression is an important arenavirus mechanism that requires investigation, as it potentially provides more detail to how such high viral loads are produced in the liver, without detection by the immune system.

In this work we have demonstrated that arenavirus infection of macrophages and hepatic cells itself can stimulate cytokine pro-inflammatory response, promotes virus replication and affects cell-cycling machinery. In line with in vitro observations and previous murine in vivo results, we have found up- 
regulation of pro-inflammatory cytokines and cell cycling genes in liver tissues of marmosets fatally-infected with LASV. Taken together with previous observations in NHPs and in a murine model of transient arenavirus hepatitis we suggest that failure of proper hepatocyte proliferation results in pathophysiological events (i.e. apoptosis, over-production of IFN-gamma, oval cells, etc.) causing major liver dysfunction, as it was demonstrated in an NHP model of arenavirus-induced liver pathology. 


\section{SUMMARY AND CONCLUSIONS}

\section{Strengths of this work}

The results presented in this thesis have many strengths. First, the results observed here demonstrate that we developed and characterized an in vitro model with RAW 264.7 macrophages and AML-12 hepatocytes that supports in vivo findings from arenavirus-induced hepatitis and can be used for further study to determine specific arenavirus mechanisms. LCMV-WE infection in these cells support data previously observed in experimental animal models: arenavirusinduced pro-inflammatory response, hepatocyte proliferation, enhanced viral replication, and evidence of cell cycle arrest. Development of this in vitro model capable of recapitulating in vivo data is a critical finding for future efforts to investigate mechanisms of arenavirus-induced liver pathology, including mechanisms of: robust viral replication, evasion of host immune response, and cell cycle arrest in cycling hepatocytes. These viral mechanisms are critically involved in progression of disease towards unregulated, systemic infection. Thus, the ability to investigate how the virus mechanistically increases infection and evades immune detection in relevant in vitro models will lead to a better understanding of how to inhibit these viral mechanisms, and thus will facilitate development of effective anti-viral therapeutics to control or prevent disease.

Furthermore, we showed upregulation of pro-inflammatory cytokines TNF and IL-6 with LCMV-WE infection in RAW 264.7 macrophages, which is the first example in the literature demonstrating an arenavirus directly induces this profile of pro-inflammatory cytokines after infection. This TNF- $\alpha$ and IL-6 cytokine 
profile, in particular, is important for early events triggering hepatocyte proliferation, which provides a potential mechanism for how arenaviruses are able to trigger the characteristic pathological hepatocyte proliferation during severe infection.

\section{Unanswered questions and future directions}

What role do TNF- $\alpha$ and IL-6 play in arenavirus-induced liver pathology?

High levels of serum IL-6 were found in human LF patients with poor prognoses and thus, IL-6 levels were correlated with disease severity $[53,89]$. However, serum TNF-a levels were not found to be elevated in patients with fatal or nonfatal LF disease [89]. Arenavirus infection in NHP animal models also resulted in high levels of IL-6 in the sera and in liver tissue, as well as elevated levels of receptors for IL-6 and TNF in the sera [26, 27, 43]. Contrary to what was expected, LCMV-WE infection in experimentally-infected mice correlated with robust induction of TNF mRNA in liver tissue, while only mild induction of IL6 mRNA was found. Though there is a similar pattern of liver pathology found in these arenavirus infections-which includes high levels of pro-inflammatory cytokines, robust pathological hepatocyte proliferation, and liver being the tissue with highest viral load-there are major differences in the profiles of proinflammatory cytokines induced with infection.

To further complicate the story, the results presented in this work demonstrated LCMV-WE infection in macrophages directly induced TNF- $\alpha$ gene expression and protein production. Building on these results, TNF- $\alpha$ stimulation 
in addition to LCMV-WE infection in AML-12 hepatocytes led to enhanced viral replication, actively cycling hepatocytes, and evidence of cell cycle arrest. Thus, here it was determined that in murine in vitro models infected with LCMV-WE, TNF- $\alpha$ is a critical pro-inflammatory cytokine involved in triggering pathological hepatocyte proliferation and also critically involved in enhancing viral replication. Based on these in vitro results plus data from liver tissue of LCMV-WE-infected mice compared to results from NHPs and human LF disease, it seems reasonable to hypothesize that TNF is yet an important cytokine in arenavirus infections, but two major THINGS are responsible for differences in its production profile in different models: 1) Timing of TNF- $\alpha$ release and function precedes severe disease state, 2) Extent of viral replication, and 3) Human versus rodent immune system.

In future experiments, it will be important to further characterize the role TNF- $\alpha$ plays in arenavirus infection in hepatocytes, particularly the signaling events and mediators downstream of TNF- $\alpha$ binding its primary receptor, TNFRI. If this receptor is blocked

How do arenaviruses infect hepatocytes in vitro and in vivo?

In spite of the fact that hepatocytes are not known to express the canonical OW arenavirus receptor, $\alpha-D G$, numerous animal studies [26, 44, 45] and human clinical findings [29, 30] have shown the liver and specifically, hepatocytes, have a high viral burden. As noted above, and in the work shown here, arenavirus infections not only trigger pathological hepatocyte proliferation, 
but also cell cycle arrest in $G_{1}$ phase. This host response of hepatocyte proliferation provides key resources needed for viral replication, like increased protein production, cell cycle factors, and energy. Furthermore, proliferating hepatocytes display more of an embryonic phenotype, which may include the expression of the canonical OW arenavirus receptor, $\alpha-D G$. $\alpha-D G$ is expressed in embryonic or developing tissues [90] and expression diminishes in adult, differentiated tissues [91, 92]. Therefore, adult, differentiated hepatocytes are not known to express glycosylated a-DG. Yet, the highest viral load during infection is found in the liver and in hepatocytes, according to findings from animal studies $[26,27,44,45]$ and human clinical data $[29,30]$. This is potentially a viral mechanism to provide new substrates for increased infection.

Thus, it is not clear how the virus infects hepatocytes in vivo or in vitro. Some unpublished results from this lab have shown positive staining for $\alpha$-DG on human hepatoma cells, HepG2, and the murine hepatocyte cells used here, AML-12. While use of $\alpha-D G$ is the preferred method of host entry for the virus, research has shown LCMV strains have varying affinities for $\alpha-D G$. LCMV-WE, the pathogenic strain, for example, displays higher affinity for $\alpha$-DG than the nonpathogenic strain, LCMV-ARM, which demonstrates low affinity [76]. Nonconventional receptors, like Axl described in this work, also have been used for OW arenavirus cell entry. Future studies are needed to determine the receptor(s) used in attachment to hepatocytes and the routes taken in entry steps. These early entry details will have important implications for host immune response and viral replication efficiency. 
What is the role of cell cycle and cell cycle arrest in productive arenavirus infection?

We show here that AML-12 hepatocytes are a useful in vitro model to further investigate mechanisms involved in pathological hepatocyte proliferation, including cell cycle arrest, and efficient pathogenic arenavirus replication. Many experiments still need to be performed to provide a better understanding of arenavirus-induced liver pathology, but the results shown here indicate the future directions to pursue next need to answer the questions: 1) Are the changes in gene expression of cell cycle mediators carried through to changes in protein levels as well? 2) If p21 or p53 are inhibited with siRNA, and thus not able to arrest cell cycle so that cells will continue to cycle into $S$ phase, then what impact will this have on LCMV-WE viral replication-will it be significantly decreased? What is role of p21 and cell cycle arrest in enhancing arenavirus infection? Does the virus use p21 directly to facilitate viral replication or does the virus indirectly allow p21 mRNA to accumulate because the virus uses a molecule related to p21 degradation for viral replication? Thus, taken together, it is important to investigate the mechanisms behind the robust increase in p21 in LCMV-WEinfected mice and murine hepatocytes and to determine the effect cell cycle manipulation has on viral replication and the effect the virus has on cell cycle as well.

\section{Conclusions}


This work has demonstrated that LCMV infection in in vitro macrophages produces high viral titers resulting in production of pro-inflammatory cytokines involved in hepatocyte proliferation. LCMV infection and TNF- cytokine stimulation of in vitro hepatocytes together displayed enhanced viral replication and altered cell cycle progression, with evidence of arrest. In good confirmation with these in vitro observations, we correlated high viral load and elevated proinflammatory IL-6 with robust increases in p21 as evidence for cell cycle arrest in liver tissue of marmosets fatally-infected with LASV. Taken together with previous observations in NHPs and in a murine model of transient arenavirus hepatitis we suggest that failure of proper hepatocyte proliferation-as observed with elevated cell cycle inhibitor p21 which is evidence of cell cycle arrestresults in pathophysiological events (i.e. apoptosis, over-production of IFNgamma, oval cells, etc.) causing major liver dysfunction, as it was demonstrated in an NHP model of arenavirus-induced liver pathology. 


\section{REFERENCES}

1. Falzarano, D. and H. Feldmann, Vaccines for viral hemorrhagic fevers-progress and shortcomings. Curr Opin Virol, 2013. 3(3): p. 343-51.

2. Borio, L., et al., Hemorrhagic fever viruses as biological weapons: medical and public health management. Jama, 2002. 287(18): p. 2391-405.

3. Jahrling, T.W.G.a.P.B., Exotic emerging viral diseases: progress and challenges. Nature Medicine Supplement, 2004. 10(12): p. S110-S121.

4. Moraz, M.L. and S. Kunz, Pathogenesis of arenavirus hemorrhagic fevers. Expert Rev Anti Infect Ther, 2011. 9(1): p. 49-59.

5. Kunz, S., The role of the vascular endothelium in arenavirus haemorrhagic fevers. Thromb Haemost, 2009. 102(6): p. 1024-9.

6. McCormick, J.B. and S.P. Fisher-Hoch, Lassa fever. Curr Top Microbiol Immunol, 2002. 262: p. 75-109.

7. Bodewes, R., et al., Detection of novel divergent arenaviruses in boid snakes with inclusion body disease in The Netherlands. J Gen Virol, 2013. 94(Pt 6): p. 1206-10.

8. Hetzel, U., et al., Isolation, identification, and characterization of novel arenaviruses, the etiological agents of boid inclusion body disease. J Virol, 2013. 87(20): p. 10918-35.

9. Stenglein, M.D., et al., Identification, characterization, and in vitro culture of highly divergent arenaviruses from boa constrictors and annulated tree boas: candidate etiological agents for snake inclusion body disease. MBio, 2012. 3(4): p. e00180-12.

10. Radoshitzky, S.R., et al., Past, present, and future of arenavirus taxonomy. Arch Virol, 2015. 160(7): p. 1851-74.

11. Fichet-Calvet, E. and D.J. Rogers, Risk maps of Lassa fever in West Africa. PLoS Negl Trop Dis, 2009. 3(3): p. e388.

12. Fisher-Hoch, S.P., et al., Review of cases of nosocomial Lassa fever in Nigeria: the high price of poor medical practice. Bmj, 1995. 311(7009): $\mathrm{p}$. 857-9.

13. Buchmeier, M.J., et al., The virology and immunobiology of lymphocytic choriomeningitis virus infection. Adv Immunol, 1980. 30: p. 275-331. 
14. Riviere, Y., et al., Genetic mapping of lymphocytic choriomeningitis virus pathogenicity: virulence in guinea pigs is associated with the $L R N A$ segment. J Virol, 1985. 55(3): p. 704-9.

15. Salvato, M.S. and E.M. Shimomaye, The completed sequence of lymphocytic choriomeningitis virus reveals a unique RNA structure and a gene for a zinc finger protein. Virology, 1989. 173(1): p. 1-10.

16. Singh, M.K., et al., Analysis of the genomic $L$ RNA segment from lymphocytic choriomeningitis virus. Virology, 1987. 161(2): p. 448-56.

17. Shao, J., Y. Liang, and H. Ly, Human hemorrhagic Fever causing arenaviruses: molecular mechanisms contributing to virus virulence and disease pathogenesis. Pathogens, 2015. 4(2): p. 283-306.

18. Kunz, S., et al., Mechanisms for lymphocytic choriomeningitis virus glycoprotein cleavage, transport, and incorporation into virions. Virology, 2003. 314(1): p. 168-78.

19. Lenz, O., et al., The Lassa virus glycoprotein precursor GP-C is proteolytically processed by subtilase SKI-1/S1P. Proc Natl Acad Sci U S A, 2001. 98(22): p. 12701-5.

20. Cao, W., Identification of -Dystroglycan as a Receptor for Lymphocytic Choriomeningitis Virus and Lassa Fever Virus. Science, 1998. 282(5396): p. 2079-2081.

21. Jae, L.T., et al., Virus entry. Lassa virus entry requires a trigger-induced receptor switch. Science, 2014. 344(6191): p. 1506-10.

22. Lukashevich, I.S., et al., Lassa and Mopeia virus replication in human monocytes/macrophages and in endothelial cells: different effects on IL-8 and TNF-alpha gene expression. J Med Virol, 1999. 59(4): p. 552-60.

23. Sevilla, N., et al., Immunosuppression and resultant viral persistence by specific viral targeting of dendritic cells. J Exp Med, 2000. 192(9): p. 1249-60.

24. Johnson, K.M., et al., Clinical virology of Lassa fever in hospitalized patients. J Infect Dis, 1987. 155(3): p. 456-64.

25. Walker, D.H., et al., Pathologic and virologic study of fatal Lassa fever in man. Am J Pathol, 1982. 107(3): p. 349-56.

26. Lukashevich, I.S., et al., Arenavirus-Mediated Liver Pathology: Acute Lymphocytic Choriomeningitis Virus Infection of Rhesus Macaques Is Characterized by High-Level Interleukin-6 Expression and Hepatocyte Proliferation. Journal of Virology, 2003. 77(3): p. 1727-1737. 
27. Hensley, L.E., et al., Pathogenesis of Lassa fever in cynomolgus macaques. Virol J, 2011. 8: p. 205.

28. Doherty, D.G., Immunity, tolerance and autoimmunity in the liver: $A$ comprehensive review. J Autoimmun, 2015.

29. McCormick, J.B., et al., Lassa virus hepatitis: a study of fatal Lassa fever in humans. Am J Trop Med Hyg, 1986. 35(2): p. 401-7.

30. Winn, W.C., Jr., et al., Lassa virus hepatitis. Observations on a fatal case from the 1972 Sierra Leone epidemic. Arch Pathol, 1975. 99(11): p. 599-604.

31. Zapata, J.C., et al., Lymphocytic choriomeningitis virus (LCMV) infection of macaques: a model for Lassa fever. Antiviral Res, 2011. 92(2): p. 125-38.

32. Doherty, P.C. and R.M. Zinkernagel, H-2 compatibility is required for T-cellmediated lysis of target cells infected with lymphocytic choriomeningitis virus. J Exp Med, 1975. 141(2): p. 502-7.

33. Zinkernagel, R.M. and P.C. Doherty, Restriction of in vitro $T$ cell-mediated cytotoxicity in lymphocytic choriomeningitis within a syngeneic or semiallogeneic system. Nature, 1974. 248(5450): p. 701-2.

34. Zinkernagel, R.M. and P.C. Doherty, Immunological surveillance against altered self components by sensitised T lymphocytes in lymphocytic choriomeningitis. Nature, 1974. 251(5475): p. 547-8.

35. Moskophidis, D., et al., Virus persistence in acutely infected immunocompetent mice by exhaustion of antiviral cytotoxic effector $T$ cells. Nature, 1993. 362(6422): p. 758-61.

36. Lukashevich, I.S., et al., Hemorrhagic fever occurs after intravenous, but not after intragastric, inoculation of rhesus macaques with lymphocytic choriomeningitis virus. J Med Virol, 2002. 67(2): p. 171-86.

37. Zinkernagel, R.M., et al., $T$ cell-mediated hepatitis in mice infected with lymphocytic choriomeningitis virus. Liver cell destruction by $\mathrm{H}-2$ class Irestricted virus-specific cytotoxic $T$ cells as a physiological correlate of the 51Cr-release assay? J Exp Med, 1986. 164(4): p. 1075-92.

38. Lukashevich, I.S., et al., LCMV-mediated hepatitis in rhesus macaques: WE but not ARM strain activates hepatocytes and induces liver regeneration. Arch Virol, 2004. 149(12): p. 2319-36.

39. Djavani, M., I.S. Lukashevich, and M.S. Salvato, Sequence comparison of the large genomic RNA segments of two strains of lymphocytic choriomeningitis virus differing in pathogenic potential for guinea pigs. Virus Genes, 1998. 17(2): p. 151-5. 
40. Asper, M., et al., First outbreak of callitrichid hepatitis in Germany: genetic characterization of the causative lymphocytic choriomeningitis virus strains. Virology, 2001. 284(2): p. 203-13.

41. Montali, R.J., et al., A common-source outbreak of callitrichid hepatitis in captive tamarins and marmosets. J Infect Dis, 1993. 167(4): p. 946-50.

42. Carrion, R., Jr., et al., Lassa virus infection in experimentally infected marmosets: liver pathology and immunophenotypic alterations in target tissues. J Virol, 2007. 81(12): p. 6482-90.

43. Baize, S., et al., Early and strong immune responses are associated with control of viral replication and recovery in lassa virus-infected cynomolgus monkeys. J Virol, 2009. 83(11): p. 5890-903.

44. Bergthaler, A., et al., Contributions of the lymphocytic choriomeningitis virus glycoprotein and polymerase to strain-specific differences in murine liver pathogenicity. J Gen Virol, 2007. 88(Pt 2): p. 592-603.

45. Beier, J.I., et al., Novel mechanism of arenavirus-induced liver pathology. PLoS One, 2015. 10(3): p. e0122839.

46. He, Y., et al., Influenza $A$ virus replication induces cell cycle arrest in G0/G1 phase. J Virol, 2010. 84(24): p. 12832-40.

47. Bian, T., et al., Respiratory syncytial virus matrix protein induces lung epithelial cell cycle arrest through a p53 dependent pathway. PLoS One, 2012. 7(5): p. e38052.

48. Davies, C., et al., Murine norovirus replication induces g0/g1 cell cycle arrest in asynchronously growing cells. J Virol, 2015. 89(11): p. 6057-66.

49. Davies, C. and V.K. Ward, Expression of the NS5 (VPg) Protein of Murine Norovirus Induces a G1/S Phase Arrest. PLoS One, 2016. 11(8): $p$. e0161582.

50. Naniche, D., S.I. Reed, and M.B. Oldstone, Cell cycle arrest during measles virus infection: a G0-like block leads to suppression of retinoblastoma protein expression. J Virol, 1999. 73(3): p. 1894-901.

51. Duronio, R.J. and Y. Xiong, Signaling pathways that control cell proliferation. Cold Spring Harb Perspect Biol, 2013. 5(3): p. a008904.

52. Sherr, C.J. and J.M. Roberts, CDK inhibitors: positive and negative regulators of G1-phase progression. Genes Dev, 1999. 13(12): p. 1501-12. 
53. Branco, L.M., et al., Emerging trends in Lassa fever: redefining the role of immunoglobulin $M$ and inflammation in diagnosing acute infection. Virol $\mathrm{J}$, 2011. 8: p. 478.

54. Taub, R., Liver regeneration: from myth to mechanism. Nat Rev Mol Cell Biol, 2004. 5(10): p. 836-47.

55. Cressman, D.E., et al., Liver failure and defective hepatocyte regeneration in interleukin-6-deficient mice. Science, 1996. 274(5291): p. 1379-83.

56. Yamada, Y., et al., Initiation of liver growth by tumor necrosis factor: deficient liver regeneration in mice lacking type I tumor necrosis factor receptor. Proc Natl Acad Sci U S A, 1997. 94(4): p. 1441-6.

57. Yamada, Y., et al., Analysis of liver regeneration in mice lacking type 1 or type 2 tumor necrosis factor receptor: requirement for type 1 but not type 2 receptor. Hepatology, 1998. 28(4): p. 959-70.

58. Cornell, R.P., B.L. Liljequist, and K.F. Bartizal, Depressed liver regeneration after partial hepatectomy of germ-free, athymic and lipopolysaccharideresistant mice. Hepatology, 1990. 11(6): p. 916-22.

59. Cornell, R.P., Gut-derived endotoxin elicits hepatotrophic factor secretion for liver regeneration. Am J Physiol, 1985. 249(5 Pt 2): p. R551-62.

60. Webber, E.M., et al., Tumor necrosis factor primes hepatocytes for DNA replication in the rat. Hepatology, 1998. 28(5): p. 1226-34.

61. Campbell, J.S., et al., Proinflammatory cytokine production in liver regeneration is Myd88-dependent, but independent of Cd14, TIr2, and TIr4. J Immunol, 2006. 176(4): p. 2522-8.

62. Hayes, M.W., et al., Pathogenic Old World arenaviruses inhibit TLR2/Maldependent proinflammatory cytokines in vitro. J Virol, 2012. 86(13): p. 721626.

63. Baize, S., et al., Lassa Virus Infection of Human Dendritic Cells and Macrophages Is Productive but Fails to Activate Cells. The Journal of Immunology, 2004. 172(5): p. 2861-2869.

64. Dong, Z., et al., The roles of innate immune cells in liver injury and regeneration. Cell Mol Immunol, 2007. 4(4): p. 241-52.

65. Smedsrod, B., et al., Hepatic sinusoidal cells in health and disease: update from the 14th International Symposium. Liver Int, 2009. 29(4): p. 490-501. 
66. Trautwein, C., et al., Acute-phase response factor, increased binding, and target gene transcription during liver regeneration. Gastroenterology, 1996. 110(6): p. 1854-62.

67. Iwai, M., et al., Increased secretion of tumour necrosis factor and interleukin 6 from isolated, perfused liver of rats after partial hepatectomy. Cytokine, 2001. 13(1): p. 60-64.

68. Fausto, N., Liver regeneration. J Hepatol, 2000. 32(1 Suppl): p. 19-31.

69. Wu, J.C., G. Merlino, and N. Fausto, Establishment and characterization of differentiated, nontransformed hepatocyte cell lines derived from mice transgenic for transforming growth factor alpha. Proc Natl Acad Sci U S A, 1994. 91(2): p. 674-8.

70. Kirillova, I., M. Chaisson, and N. Fausto, Tumor necrosis factor induces DNA replication in hepatic cells through nuclear factor kappaB activation. Cell Growth Differ, 1999. 10(12): p. 819-28.

71. Shurtleff, A.C., et al., Standardization of the filovirus plaque assay for use in preclinical studies. Viruses, 2012. 4(12): p. 3511-30.

72. Desmyter, J., J.L. Melnick, and W.E. Rawls, Defectiveness of interferon production and of rubella virus interference in a line of African green monkey kidney cells (Vero). J Virol, 1968. 2(10): p. 955-61.

73. Argast, G.M., et al., Epidermal growth factor receptor transactivation mediates tumor necrosis factor-induced hepatocyte replication. J Biol Chem, 2004. 279(33): p. 34530-6.

74. Shimojima, M., et al., Identification of cell surface molecules involved in dystroglycan-independent Lassa virus cell entry. J Virol, 2012. 86(4): p. 2067-78.

75. Rothlin, C.V., et al., TAM receptors are pleiotropic inhibitors of the innate immune response. Cell, 2007. 131(6): p. 1124-36.

76. Smelt, S.C., et al., Differences in affinity of binding of lymphocytic choriomeningitis virus strains to the cellular receptor alpha-dystroglycan correlate with viral tropism and disease kinetics. J Virol, 2001. 75(1): p. 44857.

77. Fletcher, N.F., et al., Activated macrophages promote hepatitis $C$ virus entry in a tumor necrosis factor-dependent manner. Hepatology, 2014. 59(4): $p$. 1320-30. 
78. Asper, M., et al., Inhibition of different Lassa virus strains by alpha and gamma interferons and comparison with a less pathogenic arenavirus. $\mathrm{J}$ Virol, 2004. 78(6): p. 3162-9.

79. MacParland, S.A., et al., Lipopolysaccharide and Tumor Necrosis Factor Alpha Inhibit Interferon Signaling in Hepatocytes by Increasing Ubiquitin-Like Protease 18 (USP18) Expression. J Virol, 2016. 90(12): p. 5549-60.

80. Campbell Dwyer, E.J., et al., The lymphocytic choriomeningitis virus RING protein $Z$ associates with eukaryotic initiation factor $4 E$ and selectively represses translation in a RING-dependent manner. J Virol, 2000. 74(7): p. 3293-300.

81. Djavani, M., et al., The proline-rich homeodomain (PRH/HEX) protein is down-regulated in liver during infection with lymphocytic choriomeningitis virus. J Virol, 2005. 79(4): p. 2461-73.

82. Albrecht, J.H., A.H. Meyer, and M.Y. Hu, Regulation of cyclin-dependent kinase inhibitor p21(WAF1/Cip1/Sdi1) gene expression in hepatic regeneration. Hepatology, 1997. 25(3): p. 557-63.

83. Albrecht, J.H., et al., Involvement of p21 and p27 in the regulation of CDK activity and cell cycle progression in the regenerating liver. Oncogene, 1998. 16(16): p. 2141-50.

84. Horras, C.J., C.L. Lamb, and K.A. Mitchell, Regulation of hepatocyte fate by interferon-gamma. Cytokine Growth Factor Rev, 2011. 22(1): p. 35-43.

85. Gibbs, J.D., et al., Cell cycle arrest by transforming growth factor beta1 enhances replication of respiratory syncytial virus in lung epithelial cells. J Virol, 2009. 83(23): p. 12424-31.

86. Sullivan, B.M., et al., Is the TAM receptor Axl a receptor for lymphocytic choriomeningitis virus? J Virol, 2013. 87(7): p. 4071-4.

87. Axelrod, H. and K.J. Pienta, Axl as a mediator of cellular growth and survival. Oncotarget, 2014. 5(19): p. 8818-52.

88. Qi, N., et al., Development of a spontaneous liver disease resembling autoimmune hepatitis in mice lacking tyro3, axl and mer receptor tyrosine kinases. PLoS One, 2013. 8(6): p. e66604.

89. Mahanty, S., et al., Low levels of interleukin-8 and interferon-inducible protein-10 in serum are associated with fatal infections in acute Lassa fever. J Infect Dis, 2001. 183(12): p. 1713-21.

90. Durbeej, M., et al., Distribution of dystroglycan in normal adult mouse tissues. J Histochem Cytochem, 1998. 46(4): p. 449-57. 
91. Durbeej, M., et al., Non-muscle alpha-dystroglycan is involved in epithelial development. The Journal of Cell Biology, 1995. 130(1): p. 79-91.

92. Durbeej, M., et al., Dystroglycan binding to laminin alpha1LG4 module influences epithelial morphogenesis of salivary gland and lung in vitro. Differentiation, 2001. 69(2-3): p. 121-34. 


\section{APPENDIX 1}

\section{ABBREVIATIONS}

a-DG alpha-dystroglycan

\begin{tabular}{ll} 
ALT & Alanine aminotransferase \\
AST & Aspartate aminotransferase \\
HFV & Hemorrhagic fever virus \\
HPI & Hours post-infection \\
IL-6 & Interleukin-6 \\
LASV & Lassa virus \\
LCMV & Lymphocytic choriomeningitis virus \\
LCMV-ARM & Lymphocytic choriomeningitis virus, Armstrong strain \\
LCMV-WE & Lymphocytic choriomeningitis virus, WE strain \\
LF & Lassa fever \\
LPS & Lipopolysaccharide \\
MOPV & Mopeia virus \\
NHP & Non-human primate \\
NW & New World (arenavirus) \\
OW & Old World (arenavirus) \\
TNF-a & Tumor necrosis factor alpha \\
TNFRI & Tumor necrosis factor receptor type I \\
VHF & Viral hemorrhagic fever \\
\hline
\end{tabular}




\section{APPENDIX 2}

\section{List of Premade primers (Life Technologies)}

\begin{tabular}{|c|c|c|}
\hline Gene & Species & Primer ID \\
\hline IL-6 & Mouse & Mm00446190_m1 \\
\hline TNF & Mouse & Mm00443258_m1 \\
\hline Cdk6 & Mouse & Mm01311342_m1 \\
\hline $\begin{array}{c}\text { Ccnd1 } \\
\text { cyclin D) }\end{array}$ & Mouse & Mm00432359_m1 \\
\hline \begin{tabular}{c} 
Tp53 (p53) \\
\hline $\begin{array}{c}\text { Cdkn1a } \\
\text { (p21) }\end{array}$
\end{tabular} & Mouse & Mm01731287_m1 \\
\hline Axl & Mouse & Mm04205640_g1 \\
\hline IL-6 & Human & Hs00985639_m1 \\
\hline $\begin{array}{c}\text { CCND1 } \\
\text { (CYCLIN D) }\end{array}$ & $\begin{array}{c}\text { Rhesus } \\
\text { monkey }\end{array}$ & Rh04386127_m1 \\
\hline $\begin{array}{c}\text { CDKN1A } \\
(\text { p21) }\end{array}$ & Human & Hs00355782_m1 \\
\hline \begin{tabular}{c} 
AXL \\
\hline
\end{tabular} & Human & Hs01064444_m1 \\
\hline
\end{tabular}

\section{LASV-NP primer design (Life Technologies)}

\begin{tabular}{|c|c|c|c|}
\hline Gene & Forward primer & Reverse primer & Probe \\
\hline LASV-NP & $\begin{array}{c}\text { CGA CCA CAG CAA } \\
\text { TGT TGA AG }\end{array}$ & $\begin{array}{c}\text { CCT ACC AAT TGG } \\
\text { GAT GTG AG }\end{array}$ & $\begin{array}{c}\text { TCT CTG TCT TAC } \\
\text { AAG GAG CAA GTG }\end{array}$ \\
\hline
\end{tabular}




\title{
CURRICULUM VITAE
}

\author{
Gretchen E. Holz \\ University of Louisville School of Medicine \\ Department of Pharmacology and Toxicology \\ Louisville, KY, 40202 \\ gretchen.holz@louisville.edu \\ 502-852-5394
}

\section{EDUCATION}

2010-2012 A.A. in Biology, Chemistry, Indiana University, New Albany, IN

2003-2007 B.A. in English, Gender Studies, Indiana University, Bloomington, IN

\section{PROFESSIONAL EXPERIENCE}

2012-present Graduate research assistant, Dept. of Pharmacology \& Toxicology, University of Louisville

$2012 \quad$ NIH R25 Cancer Education Program Trainee, University of Louisville

2011-2012 Undergraduate research assistant, Dept. of Chemistry, Indiana University, New Albany, IN

2011-2012 Laboratory \& teaching assistant, Dept. of Chemistry, Indiana University, New Albany, IN

$2007 \quad$ Undergraduate research assistant, Dept. of Political Science, Indiana University, Bloomington, IN

\section{PROFESSIONAL MEMBERSHIPS \& ACTIVITIES}

2014-present American Society for Virology, Student Member 
2013-present Center for Predictive Medicine for Biodefense and Emerging Infectious Diseases

\section{HONORS AND AWARDS}

06/2015 School of Interdisciplinary and Graduate Studies Travel Award

04/2015 American Society for Virology Travel Grant

2012 IPIBS Fellowship, University of Louisville School of Medicine

2012 NCI R25 University of Louisville Cancer Education Program, $\mathrm{NIH} / \mathrm{NCI}$ R25-CA134283

2012 Magna cum laude, Indiana University, New Albany, IN

2010-11 Chancellor's List, Indiana University, New Albany, IN

2007 Magna cum laude, Indiana University, Bloomington, IN

2007 Phi Beta Kappa, Gamma Chapter, Indiana University, Bloomington, IN

2005-07 Dean's List, Indiana University, Bloomington, IN

\section{FUNDING}

2012-2014 Graduate Research Fellowship, Integrated Programs in Biomedical Sciences, University of Louisville School of Medicine

$2012 \mathrm{NCl}$ R25 University of Louisville Cancer Education Program $\mathrm{NIH} / \mathrm{NCl}$ R25- CA134283

\section{ABSTRACTS AND PRESENTATIONS}

\section{ORAL PRESENTATIONS}

\section{Local/Regional}

1. Research seminar, 11/16, Pro-inflammatory cytokines promote viral replication and cell cycle mediators in arenavirus-induced hepatitis. Department of Pharmacology \& Toxicology, University of Louisville, Louisville, KY. 
2. Research seminar, $10 / 16$, TNF- $\alpha$ in LCMV-infected in vitro hepatocyte model promotes viral replication and upregulates cell cycling mediators. Virology Discussion Group, Center for Predictive Medicine for Biodefense and Emerging Infectious Diseases, University of Louisville, Louisville, KY.

3. Research seminar, 01/16, Old World Arenavirus-induced liver pathology: search for biomarkers of liver involvement in in vitro models. Virology Discussion Group, Center for Predictive Medicine for Biodefense and Emerging Infectious Diseases, University of Louisville, Louisville, KY.

4. Research seminar, 09/15, Interaction of hemorrhagic fever viruses with hepatocytes. Virology Discussion Group, Center for Predictive Medicine for Biodefense and Emerging Infectious Diseases, University of Louisville, Louisville, KY.

5. Research mini seminar, 10/14, Arenavirus interaction with hepatocytes: development of HepG2 in vitro model, Virology Research Discussion, Department of Microbiology \& Immunology, University of Louisville, Louisville, KY.

6. Research mini-seminar, 05/14, HFV-induced liver pathology: development of in vitro model, Virology Research Discussion, Department of Microbiology \& Immunology, University of Louisville, Louisville, KY.

7. Research mini-seminar, $08 / 13$, Arenavirus-induced liver pathology: the role of hepatocyte proliferation, Virology Research Discussion, Department of Microbiology \& Immunology, University of Louisville, Louisville, KY.

8. Research seminar, $03 / 13, H F V$-induced hepatocyte proliferation: the role of innate immune response, Department of Pharmacology \& Toxicology, University of Louisville, Louisville, KY.

\section{POSTERS}

\section{National/International}

1. Holz GE, Jokinen JD, Warner NL, Chung DH, Beier JI, Arteel GE, Lukashevich IS. Arenavirus-induced disruption of cell cycle progression of hepatocytes and liver pathology. (accepted) Keystone Symposia Conference: Hemorrhagic Fever Viruses, Santa Fe, New Mexico. December 4-9, 2016. 
2. Warner NL, Jokinen JD, Holz GE, Arteel GE, Lukashevich IS. Interaction of arenaviruses with polarized epithelial cells. American Society for Virology 2016 Annual Meeting, Virginia Tech, Blacksburg, Virginia.

3. Holz GE, Beier JI, Jokinen JD, Warner NL, Arteel GE, Lukashevich IS. 2015. Arenavirus-induced hepatic cell cycle arrest. American Society for Virology 2015 Annual Meeting, Western University, London, Ontario, Canada.

\section{Local/Regional}

1. Holz GE, Jokinen JD, Warner NL, Chung DH, Lukashevich IS. (2016) TNF- $\alpha$ stimulation in LCMV-infected hepatic in vitro model promotes viral replication and upregulates cell cycling machinery. Research!Louisville, Louisville. KY.

2. Holz GE, Jokinen JD, Warner NL, Arteel GE, Lukashevich IS. (2015) Arenavirus-induced liver pathology: Search for biomarkers of liver involvement in in vitro models. Research!Louisville, Louisville. KY.

3. Holz GE, Jokinen JD, Arteel GE, Lukashevich IS. (2014) Interaction of hemorrhagic fever viruses with HepG2 cells. Research!Louisville, Louisville, KY.

4. Holz GE, Beier JI, Jokinen JD, Arteel GE, Lukashevich IS. (2013) Design of tissue culture model to study interactions between macrophages and hepatocytes in arenavirus-induced liver pathology. Research!Louisville, Louisville, KY.

5. Holz GE, Beverly LJ. (2012) UBQLN1 regulates IGF1R signaling pathway. Research!Louisville, Louisville, KY.

\section{PUBLICATIONS}

\section{Published Literature}

Beier JI, Jokinen JD, Holz GE, Whang PS, Martin AM, Warner NL, Arteel GE, Lukashevich IS. Novel mechanism of arenavirus-induced liver pathology. PLoS One. 2015;10(3) 1-21. 